\title{
ON THE EXISTENCE OF OUR METALS-BASED CIVILIZATION: I. Phase Space Analysis
}

\author{
Digby D. Macdonald ${ }^{1}$ \\ Center for Electrochemical Science and Technology \\ Department of Materials Science and Engineering \\ Pennsylvania State University \\ 201 Steidle Bldg \\ University Park, PA 16802
}

Key Words: Passivity, stability, passivity breakdown, phase space analysis, metals-based civilization.

\begin{abstract}
The stability of the barrier layers of bilayer passive films that form on metal and alloy surfaces, when in contact with oxidizing aqueous environments, is explored within the framework of the Point Defect Model (PDM) using phase-space analysis (PSA), in which the rate of growth of the barrier layer into the metal, $\left(d L^{+} / d t\right)$, and the barrier layer dissolution rate, $\left(d L^{-/} d t\right)$, are plotted simultaneously against the barrier layer thickness. A point of intersection of $d L^{\%} / d t$ with $d L^{+} / d t$ indicates the existence of a metastable barrier layer with a steady state thickness greater than zero. If $d L^{*} / d t>\left(d L^{+} / d t\right)_{L=0}$, where the latter quantity is the barrier layer growth rate at zero barrier layer thickness, the barrier layer cannot exist, even as a metastable phase, as the resulting thickness would be negative. Under these conditions, the surface is depassivated and the metal may corrode at a rapid rate. Depassivation may result from a change in the oxidation state of the cation upon dissolution of the barrier layer, such that the dissolution rate becomes highly potential dependent (as in the case of transpassive dissolution of chromium-containing alloys, for example, in which the reaction $\mathrm{Cr}_{2} \mathrm{O}_{3}+5 \mathrm{H}_{2} \mathrm{O} \rightarrow 2 \mathrm{CrO}_{4}^{2-}+10 \mathrm{H}^{+}+6 e^{-}$ results in the destruction of the film), or by the action of some solution-phase species (e.g., $\left.H^{+}, C l\right)$ that enhances the dissolution rate to the extent that $d L^{-} / d t>\left(d L^{+} / d t\right)_{L=0}$. The boundaries for depassivation may be plotted in potential-pH space to develop Kinetic Stability Diagrams (KSDs) as alternatives to the classical Pourbaix diagrams for describing the conditions under which metals or alloys exist in contact with an aqueous environment. The advantage of KSDs is that they provide kinetic descriptions of the state of a metal or alloy that is in much closer concert with the kinetic phenomenon of passivity and depassivation than are equilibrium thermodynamic diagrams. Thus, KSDs more accurately account for the limits of passivity in highly acidic systems, where acid depassivation occurs, and at high potentials, where transition to the transpassive state may occur in some systems. In any event, phase space analysis of the PDM permits specification of the conditions over which reactive metals will remain passive in contact with aqueous systems and hence of the conditions that must be met for the existence of our metals-based civilization.
\end{abstract}

\footnotetext{
${ }^{I}$ E-Mail address: ddm2@psu.edu
} 


\section{Introduction}

The conditions under which passive films exist on metal surfaces is a matter of great theoretical and practical interest, because the phenomenon of passivity is the enabler for our current, metals-based civilization [1]. Thus, our industrial systems and machines are fabricated primarily from the reactive metals and their alloys, including iron, nickel, chromium, aluminum, titanium, copper, zinc, zirconium, stainless steels, nickel-base alloys, and aluminum alloys, to name but a few. In order to illustrate the reactivity of the common metals in contact with terrestrial environments, Table 1 lists the Gibbs energy changes per mole of oxide produced for the reaction of various metals with oxygen and water vapor under prototypical terrestrial conditions $\left[\mathrm{T}=25^{\circ} \mathrm{C}, p_{\mathrm{O}_{2}}=\right.$ $\left.0.21 \mathrm{~atm}, p_{\mathrm{H}_{2} \mathrm{O}}=0.02532 \mathrm{~atm}(\mathrm{RH}=80 \%), p_{\mathrm{H}_{2}}=6.156 \times 10^{-42} \mathrm{~atm}\right]$, where the partial pressure of hydrogen has been calculated from the equilibrium $\mathrm{H}_{2} \mathrm{O}(\mathrm{l}) \Leftrightarrow \mathrm{H}_{2}(\mathrm{~g})+1 / 2 \mathrm{O}_{2}(\mathrm{~g})$ for the prevailing conditions. The reader will note that all of the metals listed in Table 1 are used in our current, metals-based civilization, either in pure form or as components of alloys.

Examination of the data summarized in Table 1 show that the thermodynamic driving force for the formation of the lowest common oxide under the prevailing conditions is essentially the same, whether the metal reacts with gaseous oxygen or gaseous water (water vapor). Furthermore, all of the common, reactive metals have large negative values for the change in Gibbs energy for the reactions under prototypical terrestrial conditions, demonstrating that the formation of the oxides from the metals is thermodynamically spontaneous. Even platinum, which is commonly regarded as being "inert", spontaneously forms the $P t(I I)$ oxide, $P t O$, under these conditions. On the other hand, the change in Gibbs energy for the formation of $\mathrm{Au}_{2} \mathrm{O}_{3}$ on gold is positive, indicating that the oxide will not form spontaneously on the metal. However, in this case, we cannot exclude the formation of a two-dimensional " $A u O$ " phase on the surface (i.e., chemisorbed oxygen), as phases of this type generally form at a lower oxygen fugacity (and hence at a lower potential) than does the lowest bulk (three-dimensional) oxide.

Although the phenomenon of "passivity" has been known for about 170 years [24], and the conditions under which metals and alloys become passive have been systematically explored over the past seventy years [5-30], no unifying theoretical treatment of the limits of passivity has emerged. While many theories and models for the passive state have been developed, starting with the work of Faraday [3] and Schönbien [4] in the 1830s, and including the High Field Model (HFM) of Guntherschulze and Betz [15-17], Verwey [18], and the variants by Cabrera and Mott [19] and Fehlner and Mott [20]; the Place Exchange Mechanism (PEM) of Sato and Cohen [22]; the Interfacial Equilibrium Models (IEM) of Vetter [23], Vetter and Gorn [24], Kirchhiem [25], and Heusler [26]; and the Point Defect Model (PDM) of Macdonald and coworkers [1,27,28], to name but a few of the more prominent theories, the presently available models describe an already existing passive film and do not address the conditions under which the film may form or disappear. One of the few attempts to address the passivation/depassivation issue is that by Engell [29], who postulated that passive films can be thermodynamically stable or metastable, with film formation being governed by equilibrium thermodynamics in the first case and by the relative rates of formation and dissolution in the second. While Engell's work [29] made a valuable contribution to the 
theory of passivity, it did not resolve the theoretical issues with sufficient precision to allow specification of the exact conditions under which passivation/depassivation might occur (see below).

In this paper, the conditions under which passivity may occur are explored within the framework of the PDM using phase-space analysis (PSA). It is shown that the PDM provides a comprehensive basis for describing the formation and destruction of passive films and hence allows specification of the conditions for the use of reactive metals in our metals-based civilization. For the purpose of illustrating the processes involved, a hypothetical "Alloy X", having properties that are similar to the highly corrosion resistant $\mathrm{Ni}-\mathrm{Cr}-\mathrm{Mo}-\mathrm{W}-\mathrm{Fe}$ alloys, is employed for the calculations. However, the author stresses that Alloy X does not represent any particular alloy currently in existence or use. It is further assumed that the barrier oxide layer on the alloy is a defective chromic oxide $\left(\mathrm{Cr}_{2} \mathrm{O}_{3}\right)$, although the arguments are perfectly general and apply to any barrier layer.

\section{Background}

Passivity is normally manifest as a sharp drop in the anodic current density at a critical potential that is commonly referred to as the Flade potential (Figure 1). For many metals and alloys, the current density drops by three or more orders in magnitude leading to a corrosion rate in the passive state that is lower than that in the active state (at the active peak just negative of the Flade potential) by the corresponding factor. Thus, a generally acceptable upper limit for the corrosion rate for components in industrial systems is $10 \mu \mathrm{m} /$ year $(0.01 \mathrm{~mm} /$ year); if that were increased by a factor of 1000 to 1 $\mathrm{cm} /$ year $(10,000 \mu \mathrm{m} /$ year $)$, the use of metals in our metals-based civilization would be impractical. It is for this simple reason that passivity has been termed the "enabler of our metals based civilization" [1]. Of course, in most practical situations, the overall corrosion reaction becomes cathodically controlled by mass transport of the cathodic depolarizer to the metal surface, well before the higher rate is attained. Nevertheless, passivity is the single most important factor in enabling the use of reactive metals in corrosive environments.

At higher potentials, passivity is observed to break down on many metals and alloys and the dissolution rate of the substrate increases dramatically. This process is commonly due to the oxidative dissolution of the barrier layer; for example, in the case of chromium-containing alloys, which form chromic oxide barrier layers, the onset of transpassive dissolution is due to the reaction [31-34]

$$
\mathrm{Cr}_{2} \mathrm{O}_{3}+5 \mathrm{H}_{2} \mathrm{O} \rightarrow 2 \mathrm{CrO}_{4}{ }^{2-}+10 \mathrm{H}^{+}+6 e^{-}
$$

Note that this process results in the physical destruction of the film, such that the rate of dissolution, $d L^{-} / d t$, exceeds the rate of growth of the film at zero barrier layer thickness, $\left(d L^{+} / d t\right)_{L=0}$, (see later for nomenclature). Under these conditions, the barrier layer cannot exist under any circumstances (see below). At lower potentials, dissolution occurs via the chemical process 


$$
\mathrm{Cr}_{2} \mathrm{O}_{3}+6 \mathrm{H}^{+} \rightarrow 2 \mathrm{Cr}^{3+}+3 \mathrm{H}_{2} \mathrm{O}
$$

which is not accelerated by increasing potential, because no change (increase) in the oxidation state occurs. The potential at which the dissolution rate of $\mathrm{Cr}_{2} \mathrm{O}_{3}$ due to Reactions (1) exceeds $\left(d L^{+} / d t\right)_{L=0}$ is known as the transpassive potential, $E_{\text {trans }}$, and previous work [34,35] shows that, at this potential, the barrier layer of the passive film is destroyed. However, before the transpassive potential is reached, the electronic characters of passive films on chromium-containing alloys frequently changes from $\mathrm{n}$ type to p-type [36,37], corresponding to a change in the dominant defect in the barrier layer from the oxygen vacancy or metal interstitial to the cation vacancy. It is postulated in the PDM $[1,34]$ that the cation vacancies are produced by the oxidative ejection of cations from the barrier layer into the solution/outer layer via the reaction

$$
\mathrm{Cr}_{\mathrm{Cr}}+4 \mathrm{H}_{2} \mathrm{O} \rightarrow \mathrm{CrO}_{4}{ }^{2-}+\mathrm{V}_{\mathrm{Cr}}^{3^{\prime}}+8 \mathrm{H}^{+}+3 e^{-}
$$

which appears to become significant at potentials lower than $E_{\text {trans }}$, where the barrier layer lattice is not destroyed $[34,35]$. Note that the Kroger-Vink notation is used in Equation (3) to describe the various species in the system, with $\mathrm{Cr}_{C r}$ and $V_{C r}^{3^{\prime}}$ indicating a $\mathrm{Cr}$ (III) cation in a normal site on the cation sub-lattice and a vacancy on the same sublattice, respectively. Reaction (3) leads to enhanced cation transmission through the barrier layer, and hence to a higher current density, while Reaction (1) results in a thinner barrier layer and also leads to a higher current $\left[E_{\text {trans }},\right]$. Of great significance is the fact that, in the case of both reactions, the oxidation state of the chromium cation in the film increases by three, so that the rates of the reactions are highly potential dependent, as observed. Transpassive dissolution is observed in a great number and of metal and metal alloy systems; the critical requirement appears to be that a sufficiently large increase occurs in the oxidation state of the principal cation within the barrier layer of the passive film (e.g., $\mathrm{Cr}_{\mathrm{Cr}}$ in the $\mathrm{Cr}_{2} \mathrm{O}_{3}$ barrier layer on chromium-containing alloys) as the potential is increased in the positive direction [1].

At still higher potentials, water decomposes oxidatively to produce oxygen. The kinetics of the oxygen evolution reaction on a variety of metals and alloys have been extensively studied, and a discussion of this subject is well beyond the scope of the present article. It is sufficient to state that the mechanism of this reaction is still poorly understood and that oxygen evolution marks the upper extreme of polarization in aqueous systems. It is also important to note that, in the case of valve metals ( $\mathrm{Ti}, \mathrm{Nb}, \mathrm{Zr}, \mathrm{Al}$, etc), having rectifying passive films, oxygen evolution may not become a significant factor until very high voltages are applied.

A key question in this analysis concerns the nature of passivity of Alloy $\mathrm{X}$ in contact with oxidizing, aqueous environments. Embodied within this question is whether the passive film on the alloy is thermodynamically stable or meta-stable, and definition of the conditions under which a passive film cannot exist on the surface, even in the metastable state, thereby resulting in depassivation. The nature of passivity and depassivation is addressed in the present work within the framework of the Point Defect Model [1], which has been developed to describe, at the atomic scale, the growth and breakdown of passive films. 


\section{Point Defect Model (PDM)}

The physico-electrochemical basis of the PDM is extensively discussed in the literature (Refs. 1 and citations therein), so that only a brief description will be given here.

The PDM postulates that passive films are bilayer structures comprising highly defective barrier layers that grow into the metal and outer layers that form via the hydrolysis of cations transmitted through the barrier layer and the subsequent precipitation of a hydroxide, oxyhydroxide, or oxide, depending upon the formation conditions, or by transformation of the outer surface of the barrier layer itself (an "Ostwald ripening" process). In many systems (e.g. $\mathrm{Ni}$ and $\mathrm{Cr}$ ), the barrier layer appears to be substantially responsible for the phenomenon of passivity. In other systems, such as the valve metals and their alloys $(\mathrm{Al}, \mathrm{Ta}, \mathrm{Ti}, \mathrm{Nb}, \mathrm{Zr}, \quad$ ) and iron (particularly at elevated temperatures), for example, the outer layer may form highly resistive coating that effectively separates the reactive metal and the barrier layer from the corrosive environment. The "sealing" of anodized aluminum is an example of how the outer layer may be manipulated to achieve high corrosion resistance. In the present analysis, only the barrier layer is considered, because the theory of the formation of bilayer passive films is not well-developed (although see Refs. 38-40), and because the passivity of chromium-containing alloys appears to be due to a thin barrier layer of defective $\mathrm{Cr}_{2} \mathrm{O}_{3}$ that forms on the surface. Thus, in these cases, the barrier layer is clearly "the last line of defense".

The PDM further postulates that the point defects present in a barrier layer are, in general, cation vacancies $\left(V_{M}^{\chi^{\prime}}\right)$, oxygen vacancies $\left(V_{O}^{\bullet \bullet}\right)$, and cation interstitials $\left(M_{i}^{\chi^{+}}\right)$, as designated by the Kroger-Vink notation. Cation vacancies are electron acceptors, thereby doping the barrier layer p-type, whereas oxygen vacancies and metal interstitials are electron donors, resulting in n-type doping. Thus, on both pure metals and alloys, the barrier layer is essentially a highly doped, defect semi-conductor, as demonstrated by Mott-Schottky analysis [1], for example. Not unexpectedly, the situation with regard to alloys is somewhat more complicated than that for the pure metals. Thus, while the barrier layers on pure chromium and on $\mathrm{Fe}-\mathrm{Cr}-\mathrm{Ni}$ alloys (including the stainless steels) are commonly described as being "defective $\mathrm{Cr}_{2} \mathrm{O}_{3}$ ", that on pure chromium is normally p-type in electronic character [41], while those on the stainless steels [36,37] are n-type. It is not known whether this difference is due to doping of the barrier layer by other alloying elements, or is due to the inhibition of cation vacancy generation relative to the generation of oxygen vacancies and metal interstitials, in the barrier layer on the alloys compared with that on pure chromium. The exact details are of little consequence for the following analysis and hence they will not be explored further in this paper.

As previously discussed, the defect structure of the barrier layer can be understood in terms of the set of defect generation and annihilation reactions occurring at the metal/barrier layer interface and at the barrier layer/outer layer (solution) interface, as depicted in Figure 2 [1]. However, in analyzing the defect generation/annihilation reactions and their impact on the locations of the boundaries, it is vitally important to classify the reactions with regard to being lattice conservative (no movement of the boundary relative to the laboratory reference frame) or lattice non-conservative 
(movement of the boundary) upon their occurrence. By using the analogy of a brick wall comprising alternating red and blue bricks, and by noting that the minimum unit of the wall is an adjacent red brick/blue brick pair $\left[M O_{\chi / 2}\right.$, i.e. $M_{M}-\left(O_{O}\right)_{\chi / 2}$ in Kroger-Vink notation, or "red brick-blue brick" in the brick wall analogy, where $M_{M}$ is a cation in a normal cation sub lattice site in the barrier layer (red brick) and $O_{O}$ is an oxygen ion in a normal site on the anion sub lattice(blue brick)], it is possible to show that Reactions (1), (2), (4), (5), and (6) are lattice conservative processes, whereas Reactions (3) (oxygen vacancy generation) and (7) (barrier layer dissolution) are non-conservative. ${ }^{2}$ Note that oxygen vacancies $\left(V_{O}^{\bullet}\right)$ and cation vacancies $\left(V_{M}^{\chi^{\prime}}\right)$ can be considered as being real species ( $O_{O}$ and $M_{M}$, respectively), so that $M_{M}\left(V_{O}^{\ddot{*}}\right)_{\chi / 2}, V_{M}^{\chi^{\prime}}\left(O_{O}\right)_{\chi / 2}$, and (depending upon the context) even $V_{M}^{x^{\prime}}\left(V_{O}^{*}\right)_{\chi / 2}$ also represent minimal units of the barrier layer. Note also that the occurrence of Reaction (3) causes the barrier layer to move into the metal substrate and the dissolution Reaction (7) results in the barrier layer/outer layer interface moving in the same direction (right to left). Finally, it is evident that the occurrence of Reactions (1) and (4) and Reactions (2) and (5) simply result in the transmission of cations through the barrier layer via the existence of vacancies on the cation sub lattice or as interstitials, respectively, with the barrier layer acting as a semi-permeable membrane. In this case, the metal vacancies, $v_{m}$, injected into the metal substrate are annihilated at the metal/film interface [1] or at the (rear) free surface, resulting in the metal tending to move through the barrier layer.

Regardless of the electronic type, that is, irrespective of the identity of the dominant defect in the system, Reactions (3) and (7) are responsible for the growth and destruction of the barrier layer and any analysis of the stability of the layer must focus on these two reactions. That the barrier layer always contains oxygen vacancies is selfevident, since the rate of dissolution at the barrier layer/solution interface is always finite.

As noted elsewhere [1], the rate of change of the barrier layer thickness for a barrier layer that forms irreversibly on a metal or alloy surface can be expressed as

$$
\frac{d L}{d t}=\Omega k_{3}^{0} e^{a_{3} V} e^{b_{3} L} e^{c_{3} p H}-\Omega k_{7}^{0}\left(C_{H^{+}} / C_{H^{+}}^{0}\right)^{n} e^{a_{7} V} e^{c_{7} p H}
$$

where $a_{3}=\alpha_{3}(1-\alpha) \chi \gamma, \quad a_{7}=\alpha_{7} \alpha(\Gamma-\chi) \gamma, \quad b_{3}=-\alpha_{3} \chi \varepsilon \gamma, \quad c_{3}=-\alpha_{3} \chi \beta \gamma$, and $c_{7}=\alpha_{7} \beta(\Gamma-\chi) \gamma$ (Table 2). In these expressions, $\Omega$ is the mole volume of the barrier layer per cation, $\varepsilon$ is the electric field strength within the barrier layer (postulated to be a constant and independent of the applied voltage in the steady state, because of the buffering action of Esaki tunneling [1]), $k_{i}^{0}$ and $\alpha_{i}$ are the standard rate constant and transfer coefficient, respectively, for the appropriate reactions depicted in Figure 1 [i.e., Reactions (3) and (7)], $\alpha$ is the polarizability of the barrier layer/solution (outer layer)

\footnotetext{
${ }^{2}$ The original version of the PDM [26] did not distinguish the interfacial reactions with regard to their impact on boundary position and did not incorporate barrier layer dissolution. Consequently, the original PDM, like all other models for passive films (see above), can not account for the experimentally-observed steady states in barrier layer thickness and passive current density. The PDM was subsequently in 1991 amended to include these features.
} 
interface, (i.e., the dependence of the voltage drop across the interface, $\phi_{f / s}$, on the applied voltage, $V$ ), $\beta$ is the dependence of $\phi_{f / s}$ on $p H$ (assumed to be linear), $\gamma=F / R T, \chi$ is the oxidation state of the cation in the barrier layer, $\Gamma$ is the corresponding quantity for the cation in solution, $C_{H^{+}}$is the concentration of hydrogen ion, $C_{H^{+}}^{0}$ is the standard state concentration, and $n$ is the kinetic order of the barrier layer dissolution reaction with respect to $H^{+}$. Note that the rate of the dissolution reaction is voltage dependent if $\Gamma \neq \chi$; for $\Gamma<\chi$ (e.g. reductive dissolution of $\mathrm{Fe}_{3} \mathrm{O}_{4}$ to form $\mathrm{Fe}^{2+}$ ), the rate decreases with increasing voltage), whereas for $\delta>\chi$ (e.g. oxidative dissolution of $\mathrm{Cr}_{2} \mathrm{O}_{3}$ to form $\mathrm{CrO}_{4}^{2-}$ ) the rate increases with increasing voltage. For $\Gamma=\chi$ (e.g. dissolution of $\mathrm{Cr}_{2} \mathrm{O}_{3}$ as $\mathrm{Cr}^{3+}$ ), the rate of dissolution is voltage independent. The reader will identify the first and second terms on the right side of Equation (4) with $d L^{+} / d t$ and $d L^{-} / d t$, respectively.

By setting the left side of Equation (4) equal to zero, the steady state thickness of the barrier layer, $L_{s s}$, is readily derived as

$$
\begin{aligned}
& L_{s s}=\left[\frac{1-\alpha}{\varepsilon}-\frac{\alpha \alpha_{7}}{\alpha_{3} \varepsilon}\left(\frac{\Gamma}{\chi}-1\right)\right] V+\left[\frac{2.303 n}{\alpha_{3} \varepsilon \chi \gamma}-\frac{\alpha_{7} \beta}{\alpha_{3} \varepsilon}\left(\frac{\Gamma}{\chi}-1\right)-\frac{\beta}{\varepsilon}\right] p H \\
& +\frac{1}{\alpha_{3} \varepsilon \chi \gamma} \ln \left(\frac{k_{3}^{0}}{k_{7}^{0}}\right)
\end{aligned}
$$

which is identical to the previously published expressions [1]. For systems in the passive state, $\Gamma=\chi$, Equation (5) reduces to the somewhat simpler form of

$$
L_{s s}=\left[\frac{1-\alpha}{\varepsilon}\right] V+\left[\frac{2.303 n}{\alpha_{3} \varepsilon \chi \gamma}-\frac{\beta}{\varepsilon}\right] p H+\frac{1}{\alpha_{3} \varepsilon \chi \gamma} \ln \left(\frac{k_{3}^{0}}{k_{7}^{0}}\right)
$$

where the parameters are as previously defined. Note that in deriving these expressions, the convention has been adopted that, for the rate of barrier layer dissolution, $\mathrm{C}_{\mathrm{H}^{+}}$and $C_{H^{+}}^{0}$ have units of $\mathrm{mol} / \mathrm{cm}^{3}$, but when used for defining $\mathrm{pH}$, the units are the conventional $\mathrm{mol} / \mathrm{l}$. Thus, the standard states for the dissolution reaction [second term on the right side of Equation (4)] and for the $p H$ are $1.0 \mathrm{~mol} / \mathrm{cm}^{3}$ and $1.0 \mathrm{~mol} / 1$, respectively. The introduction of a standard state into the dissolution rate renders the units of $k_{7}^{0}$ independent of the kinetic order, $n$, without altering the numerical value of the rate.

The steady state passive current density is readily derived [1] as

$$
I_{s s}=\Gamma F\left[k_{2}^{0} e^{a_{2} V} e^{b_{2} L_{s s}} e^{c_{2} p H}+k_{4}^{0} e^{a_{4} V} e^{c_{+} p H}+k_{7}^{0} e^{a_{7} V} e^{c_{7} p H} \cdot\left(C_{H^{+}} / C_{H^{+}}^{0}\right)^{n}\right]
$$

where the first, second, and third terms arise from the generation and transport of cation interstitials, cation vacancies, and oxygen vacancies, respectively, with the term due to the latter being expressed in terms of the rate of dissolution of the barrier layer [1]. This 
expression is derived in part by noting that the fluxes of a given defect at the two defects under steady state conditions are equal; in this way the expression of the current can be formulated so as to avoid the defect concentrations at the interfaces.

\section{Phase Space Analysis}

Analysis of the stability of the barrier layer is best achieved by plotting Equation (4) in "phase space"; that is by plotting $d L^{+} / d t$ and $d L^{-} / d t$ versus $L$ as a function of the applied voltage, $p H$, and other variables, as may be deemed appropriate. For illustrative purposes, a schematic phase-space plot of Equation (4) is shown in Figure 3 for constant voltage and $p H$. As seen, the first term on the right side of Equation (4) decreases exponentially with increasing $L$, whereas the second term remains constant.

The point of intersection between $d L^{+} / d t$ and $d L^{-} / d t$ defines the steady-state film thickness, with $L_{s s}>0$ being the only physically-viable solution. Because a physicallymeaningful value of $L_{s s}$ results from a balance between the rates of film growth and dissolution at the metal/film $(\mathrm{m} / \mathrm{f})$ and film/solution ( $\mathrm{f} / \mathrm{s}$ ) interfaces, respectively, the film is only thermodynamically meta-stable. If $d L^{-} / d t \rightarrow 0$ then, from Figure $3, L_{s s} \rightarrow \infty$, corresponding to the thermodynamic equilibrium state. Another way of looking at this issue is to note that, for a system at equilibrium, the net rates of all processes in the system must be zero; that is, for the passive film $d L^{+} / d t$ and $d L^{-} / d t$ are simultaneously zero. Clearly, this is only satisfied for $d L^{+} / d t$ if $L_{s s} \rightarrow \infty$ and it is never satisfied by $d L^{-} / d t$ for any real substance. Accordingly, the equilibrium state is physically non-realizable, in contrast to the conclusion of Engell [29]. Furthermore, even if the composition of the solution is such that the outer surface of the barrier layer is at equilibrium, the barrier layer as a whole can not be at equilibrium, because of the transmission of cations as interstitials and via the cation vacancy structure. This is so, because the source of the cations (the metal) is thermodynamically less stable than is the barrier layer [this can be shown by adding Reactions (1) and (4), (2) and (5), and (3) and (7)]. Of course, one could postulate that the system might come to equilibrium once the metal ion concentration in the solution had built up to the equilibrium value for the metal. However, if this occurred, the solution would be super saturated with respect to the barrier layer (and more so with respect to the outer layer) and precipitation would occur continuously until the metal was consumed. Again, the passive film can not be in a state of equilibrium and the previously held notion that it is (or can be) must be abandoned.

It is evident from Figure 3 that the physical condition that must be met for the barrier layer to exist on the surface is

$$
\left(\frac{d L^{+}}{d t}\right)_{L=0}>\frac{d L^{-}}{d t}
$$

This condition is equivalent to specifying that $L_{s s}>0$. As is shown below, depassivation, particularly that due to transition to the transpassive state, is a catastrophic event that occurs over a minuscule change in an appropriate independent variable 
(potential or $p H$ ). Accordingly, for the purposes of defining the boundary between the passivated and depassivated states, the inequalities may be replaced by equalities to read:

$$
\left(\frac{d L^{+}}{d t}\right)_{L=0}=\frac{d L^{-}}{d t} \text { or } L_{s s}=0
$$

Equations (8) and (9) are, in a very literal sense, a statement of the conditions that must be met for the use of reactive metals in aqueous environments and hence the conditions that had to have been met for the development of our metals-based civilization.

In applying phase space analysis, the set of parameter values summarized in Table 4 are employed. These values are typical of those recently determined by Macdonald, et al. [42], for Alloy 22 in saturated $\mathrm{NaCl}$ brine and for iron in caustic $(\mathrm{NaOH})$ solutions [43], but the selected parameter values have been arbitrarily changed, so that the reader cannot take the values as being representative of those particular systems. This was done, because the studies in determining the parameter values are incomplete. Finally, the current treatment is valid only for acidic systems, where the dissolution rate is a positive function of $\left[H^{+}\right]$. Specifically, this requires that $p H \ll p z c$, where $p z c$ is the $p H$ of zero charge for the oxide comprising the barrier layer. A more complete theory, one that covers the entire $\mathrm{pH}$ range, is currently being developed by the author.

\section{Transition to the Transpassive State}

Phase space plots for Alloy $\mathrm{X}$ in acidified $(\mathrm{pH}=3), 6.256 \mathrm{~m}$ (sat.) $\mathrm{NaCl}$ at $50^{\circ} \mathrm{C}$ are shown in Figure 4. Two sets of plots are presented, linear-linear (a) and log-linear (b) plots, because of the difficulty of presenting the entire phenomenon on a single scale for the ordinate. As expected, the dissolution rate of the barrier layer, $d L^{-} / d t$, in the passive state, is potential independent, whereas the film growth rate increases with increasing voltage for a constant barrier layer thickness [see Equation (40) with $\chi=\Gamma$ ]. The values of $\left(d L^{+} / d t\right)_{L=0}$ are not shown in Figure $4(\mathrm{a})$, because of the scale chosen for the ordinate, but they are evident in Figure 4(b). As noted above, the point of intersection of $d L^{+} / d t$ and $d L^{-} / d t$ defines the steady state thickness, which is plotted as a function of voltage in Figure 5. In the passive range, where $\Gamma=\chi=3$, the barrier layer thickness varies linearly with voltage with a slope of $(1-\alpha) / \varepsilon=1.5 \mathrm{~nm} / \mathrm{V}$, which is typical of barrier layer growth. At $\mathrm{V}=0.9957 \mathrm{~V}_{\mathrm{SHE}}$, the oxidation state of chromium, $\Gamma$, in the dissolution product increases to from 3 to 6 (chromate formation), and the thickness of the barrier layer is predicted to become negative (i.e., zero). This sudden, catastrophic destruction of the barrier layer marks the transition of the system into the transpassive state [34,35].

The origin of the catastrophic destruction of the barrier layer is revealed in Figure 6 , in which the initial growth rate of the film at the metal/barrier layer interface, $\left(d L^{+} / d t\right)_{L=0}$, and the dissolution rate, $d L^{-} / d t$, are plotted against voltage. The initial barrier layer growth rate increases linearly with voltage through the critical transpassive potential, $E_{\text {trans }}=0.9975 \mathrm{~V}_{\mathrm{SHE}}$, but the dissolution rate increases abruptly at $E_{\text {trans }}$, such that $d L^{-} / d t>\left(d L^{+} / d t\right)_{L=0}$. Thus, the transition into the transpassive state is induced 
by enhanced dissolution of the barrier layer at the barrier layer/solution interface, in a manner that leads to a catastrophic loss of the barrier layer.

Depassivation also occurs at very negative voltages, due to the barrier layer thickness extrapolating to zero. This may occur, because the film is electrochemically reduced to the metal, e.g. $\mathrm{Cr}_{2} \mathrm{O}_{3}+6 \mathrm{H}^{+}+6 e^{-} \rightarrow 2 \mathrm{Cr}+3 \mathrm{H}_{2} \mathrm{O}$, or because it is reduced to a lower oxidation state species in the solution $\left[\mathrm{Cr}_{2} \mathrm{O}_{3}+6 \mathrm{H}^{+}+2 e^{-} \rightarrow 2 \mathrm{Cr}^{2+}+3 \mathrm{H}_{2} \mathrm{O}\right]$. In this latter case, $\Gamma$ is less than $\chi$. At lower potentials, the system enters the passive-to-active transition. It is evident, then, that the passive state exists between these two extremes.

From Equation (5) or, equivalently, by setting $d L^{-} / d t=\left(d L^{+} / d t\right)_{L=0}$, the following equation is derived for the value of the oxidation state of the metal species produced by dissolution of the barrier layer above which catastrophic loss of the barrier layer occurs at high potentials:

$$
\Gamma_{c r}=\chi\left(1+Z_{c r}\right)
$$

where

$$
Z_{c r}=\frac{(1-\alpha)\left(\frac{\alpha_{3}}{\alpha_{7}}\right) E_{\text {trans }}+\left(\frac{2.303 n}{\alpha_{7} \chi \gamma}-\frac{\alpha_{3} \beta}{\alpha_{7}}\right) p H+\frac{1}{\alpha_{7} \chi \gamma} \ln \left(\frac{k_{3}^{0}}{k_{7}^{0}}\right)}{\alpha E_{\text {trans }}+\beta p H}
$$

with the parameters being as previously defined. Note that, for the electro dissolution of the $\mathrm{Cr}_{2} \mathrm{O}_{3}$ barrier layer [Reaction (1)],

$$
E_{\text {trans }}=E^{e}=\frac{2.303 R T}{F}\left(\frac{1}{3}\right) \log \left(a_{\mathrm{CrO}_{4}^{2-}}\right)-\frac{2.303 R T}{F}\left(\frac{4}{3}\right) p H
$$

where (in this case) the activity of chromate ion is calculated from the equilibrium

$$
2 \mathrm{Cr}_{2} \mathrm{O}_{3}+4 \mathrm{H}_{2} \mathrm{O}+3 \mathrm{O}_{2}=4 \mathrm{CrO}_{4}^{2-}+8 \mathrm{H}^{+}
$$

subject to the constraint imposed by the solubility of sodium chromate

$$
\mathrm{NaCrO}_{4}=\mathrm{Na}^{+}+\mathrm{CrO}_{4}^{2-}
$$

(Note that the passive film on the Alloy X surface is assumed to be in contact with a thin, saturated solution of $\mathrm{NaCl}$ ).

Substitution of values for the parameters shows that for $0<p H<6$, the region over which the current theory has been developed, $\Gamma_{\min }=3.7162$, regardless of the applied voltage. Because oxidation states (in this system) change in units, it is concluded that there are no circumstances for which the potential is greater than $E_{\text {trans }}$ that the barrier layer can exist. An increase in the oxidation state of chromium in the barrier layer, alone, 
upon dissolution, is sufficient to cause the catastrophic loss of the barrier layer at $E_{\text {trans }}$. Thus, even if the barrier layer dissolved to produce a $\mathrm{Cr}(\mathrm{IV})$ species (e.g., $\mathrm{CrO}_{3}^{2-}$ ), transition to the transpassive state is predicted. Indeed, nickel in borate buffer solution at $\mathrm{pH}=8.6$, exhibits a transition into the transpassive state, as indicated by the sudden drop in the interfacial impedance, and it appears that this transition is induced by a change in nickel oxidation state from 2 to 3 [44].

Plots of the calculated partial current densities for the generation of oxygen vacancies at the metal/barrier layer interface (Reaction 3, Figure 2) $\left(I_{O V}\right)$, generation and annihilation of cation interstitials, $I_{C I}$, (Reactions 2 and 5, respectively, Figure 2); generation and annihilation of cation vacancies, $I_{C V}$, (Reactions 1 and 4, respectively, Figure 2); and barrier layer dissolution, $I_{\text {diss }}$, (Reaction 7, Figure 2); and the total current density $\left(I_{t o t}\right)$, as a function of voltage, are shown in Figure 7, in which both linear-linear (a) and log-linear (b) plots are presented. The plots show that the partial current densities due to the generation of oxygen vacancies and cation interstitials are independent of voltage within the passive state (note that $\Gamma=\chi$ for the passive state), while the partial current density for the generation of cation vacancies increases exponentially with voltage. Note also that the partial current density for barrier layer dissolution is zero within the passive state $(\Gamma=\chi)$. All of these partial current densities, and hence the total current density, abruptly increase when the potential exceeds $E_{\text {trans. }}$. Of particular importance is the abrupt increase in the barrier layer dissolution current density, which leads to the destruction of the film. For all four currents, the fundamental cause of the sudden increase is the change in oxidation state of the dissolved species from 3 to 6 .

Also shown in this figure is the potential at which the cation vacancy partial current dominates the total current density. At more negative potentials, the dominant defects in the barrier layer are the oxygen vacancy and the cation interstitial, both of which are electron donors and hence dope the barrier layer n-type. At higher potentials, the dominant defect is the cation vacancy, which is an electron acceptor and hence dopes the barrier layer p-type. It is also evident that the total current exhibits a Tafel-like behavior, which is often found in the "pre-transpassive" state.

Finally, it is important to note that the barrier layer may undergo reductive dissolution, as noted above. In this case, $\Gamma<\chi$, so that the dissolution rate is predicted to increase abruptly as the potential is displaced in the negative direction past the value for transition to the sub passive state. This case is readily accommodated by the above theory with $E_{s u b}$ being equal to the equilibrium potential for the barrier layer dissolution reaction, e.g. $\mathrm{Cr}_{2} \mathrm{O}_{3}+6 \mathrm{H}^{+}+2 e^{-} \rightarrow 2 \mathrm{Cr}^{2+}+3 \mathrm{H}_{2} \mathrm{O}$. However, there are few reactive metals for which the transition to the sub passive state is of practical interest, because of the intervention of hydrogen evolution prior to attaining $E_{s u b}$ when displacing the potential in the negative direction.

\section{Acid Depassivation}

Log-linear phase space plots for Alloy $\mathrm{X}$ as a function of $\mathrm{pH}$ are shown in Figure 8. From these plots, it is evident that the barrier layer growth rate is only weakly dependent upon $p H$; this is primarily due to the small value of $\beta$. On the other hand, the dissolution rate of the barrier layer is a strong function of the concentration of $\mathrm{H}^{+}$, by virtue of the value of the kinetic order, $n$. In any event, the thickness of the steady state 
barrier layer is predicted to decrease sharply with decreasing $p H$, such that at $p H=$ 1.2657 , the barrier layer is destroyed (Figure 9). At this point, the surface has become depassivated and the substrate dissolves rapidly in the passive-to-active transition, depending upon the applied potential and the kinetics of the metal (active) dissolution reaction.

A more explicit demonstration of the fundamental cause of acid depassivation is shown in Figure 10. In this figure, the initial film growth rate and the dissolution rate are plotted as a function of $p H$, demonstrating that the two functions intersect at $p H=$ 1.2657. Thus, for a lower $p H<-1.237, d L^{-} / d t>\left(d L^{+} / d t\right)_{L=0}$, and the barrier layer cannot exist on the surface, even as a metastable phase.

Log-linear plots of the partial and total current densities as a function of $p H$ are displayed in Figure 11. In this case, the partial current densities due to cation interstitials and oxygen vacancies vary exponentially with $p H$, while that for cation vacancies is predicted to be essentially independent of $p H$. This is because the current densities for the generation of cation interstitials and oxygen vacancies at the metal/film interface are not functions of the respective defect concentrations at that interface, whereas they are functions of the defect concentrations at the barrier layer/solution interface and an expression of the current densities, based on the reactions at the barrier layer/solution interface, would require knowledge of these concentrations [27]. The rate constants for these reactions are exponentially dependent upon the $p H$ and the barrier layer thickness, with the latter being a linear function of $p H-$ Figure 9 . It is the barrier layer thickness that dominates the $p H$-dependence of the partial currents for the generation of cation interstitials and oxygen vacancies, and it is for this reason that the currents depend exponentially on $p H$. On the other hand, for cation vacancy generation, Reaction (4), Figure 2, the partial current does not depend on the thickness and, because of the value of $\beta$, the dependence of $I_{C V}$ on $\mathrm{pH}$ is very weak. Finally, for the parameter values chosen for this study, the cation interstitial current density dominates the total current density over the entire range of $\mathrm{pH}$ assumed.

Because the corrosion rate is readily calculated from the total current density that passes across the interface, as

$$
C R=\frac{M}{\Gamma F \rho} I_{T o t}
$$

where $\Gamma, M$, and $\rho$ are the oxidation number, atomic weight, and density of the metal, respectively, and $F$ is Faraday's constant ( $\mathrm{F}=96,487 \mathrm{C} /$ equiv). Values for $\Gamma, M$, and $\rho$ of $2,60 \mathrm{~g} / \mathrm{mol}$, and $8 \mathrm{~g} / \mathrm{cm}^{3}$, respectively, were selected. As expected, the corrosion rate is also a falling exponential function of $p H$, with values ranging from a little more than $40 \mu \mathrm{m} /$ year at the point of acid depassivation to $0.0045 \mu \mathrm{m} /$ year at $p H=6$ (Figure 12). These values are eminently reasonable for highly corrosion resistant alloys.

Finally, it should be noted that a comparable depassivation phenomenon occurs at very high $p H$, for those systems where the barrier layer dissolves at an increasing rate with increasing $p H$. Both acid depassivation and alkaline depassivation can be accommodated in a single theory by redefining the dissolution rate as

$$
\frac{d L^{-}}{d t}=\Omega k_{7}^{0}\left(C_{H^{+}} / C_{H^{+}}^{0}\right)^{n} e^{a_{7} V} e^{c_{7} p H}+\Omega k_{8}^{0}\left(C_{O H^{-}} / C_{O H^{-}}^{0}\right)^{m} e^{a_{8} V} e^{c_{8} p H}
$$


where the second term on the right side of Equation (16) corresponds to the dissolution rate of the barrier layer via attack by hydroxide ion, e.g.

$$
M O_{\chi / 2}+\delta \mathrm{OH}^{-} \stackrel{k_{8}}{\longrightarrow} M \mathrm{OO}_{\chi / 2}(\mathrm{OH})_{\delta}^{(\delta+\chi-\Gamma)-}+(\Gamma-\chi) e^{-}
$$

and $m$ is the kinetic order of the reaction with respect to [OH]. The value of $k_{8}$ is such that the two terms on the right side of Equation (16) are equal at the $p z c$ (pH of zero charge) of the barrier layer. However, note that the values of $n$ and $m$ may be functions of $\mathrm{pH}$.

\section{Effect of Temperature}

The predicted effect of temperature on the phase space plots for Alloy $\mathrm{X}$ in $6.256 \mathrm{~m}$ (sat.) $\mathrm{NaCl}$ at $50^{\circ} \mathrm{C}$ and at a voltage of $0.300 \mathrm{~V}_{\mathrm{SHE}}$ is shown in Figure 13. In this case, the ordinate data are plotted on the log scale, so that the phase space plots appear as linear relationships. As seen from Figure 13, increasing temperature shifts both $d L^{-} / d t$ and $\left(d L^{+} / d t\right)_{L=0}$ to higher values, in a manner that the steady state barrier layer thickness is predicted to be only weakly dependent on temperature. The shift is such that thermal depassivation is not predicted, at least for systems under ordinary conditions. Thermal depassivation will not be considered further in this paper.

\section{Kinetic Stability Diagrams}

The great contribution of Marcel Pourbaix in developing potential-pH ("Pourbaix") diagrams is firmly recognized in electrochemistry and corrosion science and these diagrams have proven to be powerful tools in analyzing physico-electrochemical phenomena in fields ranging from electrochemistry to geochemistry. However, the diagrams provide equilibrium thermodynamic descriptions of electrochemical systems, whereas, as demonstrated above, passivity is a kinetic phenomenon. The limitation of Pourbaix diagrams in interpreting passivity is well illustrated by the author's resolution of Faraday's paradox $[1,45]$, which showed that the passivity of iron observed by Faraday in concentrated nitric acid can only be accounted for by the formation of a metastable magnetite $\left(\mathrm{Fe}_{3} \mathrm{O}_{4}\right)$ barrier layer covered by an outer layer of a precipitated $\mathrm{Fe}$ (III) hydroxide, oxyhydroxide, or oxide.

The reader will recall that the condition for depassivation is given by $L_{s s}=0$ [Equation (5)]. The reader will further recall that the conditions for electrochemical depassivation are $\Gamma>\Gamma_{\min }$ or $V>E_{\text {trans }}$ (oxidative depassivation or transition to the transpassive state), $\Gamma<\Gamma_{\max }$ (reductive film dissolution), $p H<p H_{\min }$ (acid depassivation), or $p H>p H_{\max }$ (alkaline depassivation), such that $d L^{-} / d t>$ $\left(d L^{+} / d t\right)_{L=0}$. For those cases where no change in oxidation state occurs upon dissolution of the barrier layer (e.g., acid and alkaline depassivation), $\Gamma=\chi$. The voltage at which the barrier layer has zero thickness, $V_{Z T}$, for a given $p H$, and the $p H$ at which the thickness is zero for a given voltage, $p H_{\text {depass, }}$, within the acid depassivation region, are obtained from Equation (5) as 


$$
\begin{aligned}
& V_{Z T}=\left[\left(2.303 n+c_{3}-c_{7}\right) p H+\ln \left(k_{3}^{0} / k_{7}^{0}\right)\right] /\left(a_{7}-a_{3}\right) \\
& p H_{\text {depass }}=\left[\left(a_{7}-a_{3}\right) V-\ln \left(k_{3}^{0} / k_{7}^{0}\right)\right] /\left(2.303 n+c_{3}-c_{7}\right)
\end{aligned}
$$

respectively. The importance of Equation (5) is therefore evident; this single equation describes the conditions that must be met for the existence of our reactive metals-based civilization.

The conditions specified above may be used to develop "kinetic stability diagrams (KSDs)" as alternatives to the classical Pourbaix diagrams, noting that KSDs are kinetic descriptions of the passive state and hence are not encumbered by the need for the system to be at electrochemical equilibrium; a condition that never exists in the passive state, as demonstrated earlier in this paper. A primitive KSD for Alloy X under acidic conditions at $50^{\circ} \mathrm{C}$ is shown in Figure 14; a more complete treatment of KSDs will be published at a later date. The figure is divided into three regions; the transpassive state for potentials more positive than $E_{\text {trans }}$, the passive state at lower potentials, and the depassivated state at the most negative potentials and the most acidic systems. The boundary between the passive and depassivated states can be described by either Equation (18) or (19), depending on whether $p H$ [Equation (18)] or voltage [Equation (19)] is considered to be the independent variable. Both equations are plotted in Figure 14 to demonstrate that they must yield identical results, because they stem from the same source [Equation (5)].

Finally, the KSD indicates that Alloy $X$ should be passive at very low $\mathrm{pH}$ values over a significant range of voltage, a prediction that is in keeping with observation for highly resistant stainless steels and $\mathrm{Ni}-\mathrm{Cr}$ alloys, but which is not predicted by the classical Pourbaix diagrams. Also, no need exists to specify the activities of dissolved species (other than that of $H^{+}$), unless the reactions are reversible (near equilibrium), which generally is not the case for passive systems. This factor alone removes a great ambiguity with the Pourbaix diagrams.

\section{Other Models}

A number of other models and theories for the passive state [1-29] have been proposed since the pioneering work of Faraday [4] and Schoenbein [3], and it is of interest to determine whether these models and theories, too, might form a suitable basis for describing the passivity of reactive metals. From the phase space analyses presented above, it is evident that a viable model must incorporate two important features: (1) Dissolution of the barrier layer, and (2) prediction of a finite value of $\left(d L^{+} / d t\right)_{L=0}$. If either of these elements is absent in the theory or model, the theory or model cannot account for the known experimental data, as discussed below.

The most extensively used model for the passive state originates from the initial work of Guntherschulze and Betz [15-17] and Verwey [18], or variants thereof, such as the high field model (HFM) of Cabrera and Mott [19] and Fehlner and Mott [20]. None of these models incorporate dissolution of the barrier layer and could be rejected on those grounds alone, since they cannot account for the existence of steady states in barrier layer thickness and passive current density [1]. However, variants of the high field model that do incorporate barrier layer dissolution have been developed [46] and, ostensibly, remove this objection. Of much greater difficulty is the form of the equation that describes the growth of the film under potentiostatic conditions 


$$
\frac{d L}{d t}=A e^{B / L}
$$

where $A$ and $B$ are constants. Thus, as $L \rightarrow 0, d L / d t \rightarrow \infty$, demonstrating that the condition $d L^{-} / d t>\left(d L^{+} / d t\right)_{L=0}$ can never exist and hence that depassivation, including the transition to the transpassive state can never occur. This is in direct conflict with experiment. It is possible, of course, to impose the ad hoc condition that when $L<$ $L_{0}$, where $L_{0}$ is an arbitrarily chosen dimension, that $\left(d L^{+} / d t\right)_{L=0}=$ constant, but this would violate Einstein's admonishment to the scientific community that one should not introduce features on an ad hoc basis simply to make a theory 'work'. Accordingly, this approach must be rejected as lacking a physical or experimental basis, as must any model that is characterized by a growth rate law of the form descried by Equation (20). This objection to the HFM is added to a long list of other objections $[1,21,46,47]$, with the result that the high field model must be rejected as a physical description of passive film growth, on this ground and on the lack of film dissolution.

According to Olsson and Landolt [6], the film growth equation for all interface models [IFM:s] can be written in the form

$$
\frac{d L}{d t}=k_{I}^{i f} e^{k_{2}\left[\Delta U-E_{0} \Delta L\right]}
$$

where $k_{I}^{i f}$ and $k_{2}$ are constants with different meanings, depending upon the model being considered, $\Delta U$ is the applied voltage, and: "The film will show a thickness change $\Delta L$ until the potential across the film is balanced. For the IFM, the thickness change is found in the nominator and the growth rate is not explicitly dependent on the absolute film thickness" (?). Examination of one of the models cited by Olsson and Landolt [6], that of Vetter and Gorn [24], for example, shows that the above claim [that the rate law has the form of Equation (21)] is not justified by the properties of the model, as presented by the original authors. Thus, using the notation of Vetter and Gorn, as much as possible, it is evident that the voltage applied across the film can be written as

$$
V=\varepsilon_{1,2}+|\varepsilon| L+\varepsilon_{2,3} \text { and hence } \varepsilon_{2,3}=V-\varepsilon_{1,2}-|\varepsilon| L
$$

where $\varepsilon_{1,2}, \varepsilon_{2,3}, \varepsilon$, and $L$ are the potential drop across the metal/film interface, the potential drop across the film/solution interface, the electric field strength, and the film thickness, respectively. Because film growth/dissolution is envisioned to occur at the film/solution interface, the rate of change of the film thickness can be written as

$$
\frac{d L}{d t}=A e^{-b \varepsilon_{1,2}} e^{b V} e^{-b|\varepsilon| L}
$$

where $A$ is a constant, $b=\alpha F / R T, \alpha$ is a transfer coefficient, and the other parameters have their usual electrochemical meanings. Equation (23) is coincident with Equations 
(21) and (4), only if $\varepsilon_{1,2}$ and $\varepsilon$ are independent of the applied voltage. However, there is nothing in the paper of Vetter and Gorn [24] that would justify a postulate that $\varepsilon_{1,2}$ and $\varepsilon$ are independent of the applied voltage and film thickness, and there is nothing in that paper or other papers by the authors, which the present author can discern, that indicates that they entertained that these assumptions could be made. Indeed, as near as present author can determine, all interface control models that envision film growth to occur at the film/solution interface (as opposed to the metal/film interface, as envisioned by the PDM) have this same weakness. In any event, Equation (21) contains only a single term on the right hand side and hence no steady state in the film thickness can exist.

One other class of models, the Place Exchange Models (PEMs), or variants thereof, of Eley and Wilkinson [47], Sato and Cohen [22], and Fehlner and Mott [20] do yield a rate law with the correct functional form for the growth term with respect to the dependence on film thickness [first term of Equation (4)]. For example, Eley and Wilkinson [47] postulated that the activation energy for film growth increased linearly with thickness and noted that this postulate could account for the logarithmic rate law. Sato and Cohen [22], in their elegant work on the growth of passive films on iron in borate buffer solution, noted that the growth current decreased exponentially with the accumulated charge. Since the film thickness is proportional to the accumulated charge, the Sato and Cohen findings are consistent with the postulate of Eley and Wilkinson [47]. Fehlner and Mott [20] further assumed that the electric field strength is independent of film thickness, that film growth occurs via the transmission of anions through the film, that the rate determining step is the injection of oxygen ions into the film at the film solution interface, and that the activation energy for the rate-determining step increases linearly with film thickness by "whatever the mechanism is". These postulates may be compared with those of the PDM summarized earlier in this paper. However, none of the models discussed above incorporate film dissolution and hence the rate law contains only a single term. As noted above, models of this type cannot account for the existence of steady states in the voltage and current and are not amenable to phase space analysis.

\section{Summary and Conclusions}

The conditions under which reactive metals can exist within the passive state and hence may be used in our metals based civilization have been explored by phase space analysis (PSA) within the framework of the Point Defect Model (PDM). PSA demonstrates that a steady state in barrier layer thickness and passive current density exists only at the point of intersection of $d L^{+} / d t$ and $d L^{-} / d t$, where $d L^{+} / d t$ and $d L^{-} / d t$ are the rates of barrier layer growth at the metal/barrier layer interface and dissolution of the barrier layer at the barrier layer/solution interface, respectively, with the former being a decreasing exponential function of the barrier layer thickness. PSA also demonstrates that a passive film cannot exist in an equilibrium state and hence that the barrier layers of passive films on reactive metals and alloys in contact with oxidizing aqueous environments are meta stable in nature. Furthermore, PSA shows that, for a passive film (barrier layer) to exist on the metal surface, $\left(d L^{+} / d t\right)_{L=0}>d L^{-} / d t$. Violation of this condition occurs upon the transition of the system into the transpassive 
state, resulting in a sudden increase in the film dissolution rate brought about by an increase in the oxidation state of the dissolving species at the transition potential, $E_{\text {trans }}$. Alternatively, depassivation may occur due to a combination of a change in growth rate and/or film dissolution rate brought about by a causative agent in solution $\left(\mathrm{H}^{+}\right.$, as in the case of acid depassivation). In this latter case, no change in oxidation state is required. All of these depassivation phenomena can be described and predicted by a single equation, $L_{s s}=0$ or equivalently $\left(d L^{+} / d t\right)_{L=0}=d L^{-} / d t$. Finally, kinetic stability diagrams (KSDs), in which the regions of transpassive dissolution and depassivation are delineated from the passive state, are proposed as alternatives to the classical Pourbaix diagrams for describing the electrochemical states of passive metals and alloys in potential-pH space.

\section{Acknowledgments}

The author gratefully acknowledges the support of this work by the US Department of Energy via Subcontract A20257JG1S from Innovation Design Technologies Inc., Henderson, Nevada 


\section{References}

1. D. D. Macdonald, Pure Appl. Chem., 71, 951 (1999).

2. H. Uhlig, in Passivity of Metals (R. P. Frankenthal and J. Kruger, eds), The Electrochemical Society, Princeton, NJ, 1978, p. 1.

3. C. Schönbein, Pogg. Ann. 37, 390 (1836). Reprinted in 1965.

4. M. Faraday, Experimental Researches, in Electricity, 2, 234 (reprinted1965), Dover, NY.

5. J. W. Schultze and M. M. Lohrengel, Electrochim. Acta, 45, 2499 (2000).

6. C.-O. A.Olsson and D. Landolt, Electrochim. Acta, 48, 1093 (2003).

7. International Symposium on Passivity, Schloss Heiligenberg, Germany; Z. Elektrochem., 62, 619 -827 (1958).

8. The Second International Symposium on Passivity, Toronto, Canada; J. Electrochem. Soc., 110 (1963); ibid, 111 (1964).

9. The Third International Symposium on Passivity, Cambridge, UK, 1970; Electrochim. Acta., 15 (1970); ibid, 16 (1971).

10. The Fourth International Symposium on Passivity, Airlie, VA; published as Passivity of Metals (R. P. Frankenthal and J. Kruger, Eds), The Electrochemical Society, Princeton, NJ, 1978.

11. The Fifth International Symposium on Passivity, Bombannes, France, 1983; published as Passivity of Metals and Semiconductors (M. Froment, Ed), Elsevier, Amsterdam, 1983.

12. The Sixth International Symposium on Passivity, Sapporo, Japan, 1989; published as Passivity of Metals and Semiconductors (N. Sato and K. Hashimoto, Eds), Pergamon Press, Oxford, UK, 1990.

13. The Seventh International Symposium on Passivity, Passivation of Metals and Semiconductors, Clausthal, Germany, 1994; published as a Special Issue of Mater. Sci. Forum,(K. Heusler, Ed.) 185-188 (1995).

14. The Eighth International Symposium on Passivity of Metals and Semiconductors, Jasper, Alberta, Canada, May 9-14, 1999; Symposium Proceedings published by The Electrochemical Society, (M. B. Ives, Ed.), 2001.

15. A. Guntherschulze and H. Betz, Z. Phys. 68, 145 (1931).

16. A. Guntherschulze and H. Betz, Z. Elekrochem., 37, 726 (1931).

17. A. Guntherschulze and H. Betz, Z. Phys., 92, 367 (1934).

18. E. J. W. Verwey, Physica, 2, 1059 (1935).

19. N. Cabrera and N. F. Mott, Rep. Progr. Phys., 12,163 (1948-1949).

20. F. P. Fehlner and N. F. Mott, Oxidat. Met., 2, 59 (1970).

21. L. Young, Anodic Oxide Films, Academic Press, London, 1961.

22. N. Sato and M. Cohen, J. Electrochem. Soc., 111, 512 (1964).

23. K. J. Vetter, Electrochim. Acta, 16, 1923 (1971).

24. K. J. Vetter and F. Gorn, Electrochim. Acta, 18, 321 (1973).

25. R. Kirchheim, Electrochim. Acta, 32, 1619 (1987).

26. C.-Y. Chao, L.-F. Lin, and D. D. Macdonald, J. Electrochem. Soc., 128, 1187 (1981).

27. D. D. Macdonald, S. R. Biaggio, and H. Song. J. Electrochem. Soc., 139, 170-177 (1992). 
28. K. E. Heusler, Corros. Sci., 31, 597 (1990).

29. H. J. Engell, Electrochim. Acta, 22, 987 (1977).

30. N. Sato, Passivity of Metals (R. P. Frankenthal and J. Kruger, eds), The Electrochemical Society, Princeton, NJ, 1978, p. 29.

31. C.-O. A.Olsson, D. Hamm, and D. Landolt, J. Electrochem. Soc., 147, 4093 (2000).

32. C.-O. A.Olsson, M.-G. Verge, and D. Landolt, J. Electrochem. Soc., 151, B652 (2004).

33. M.-G. Verge, C.-O. A.Olsson, and D. Landolt, Corros. Sci., 46, 2583 (2004).

34. D. D. Macdonald, "Theory of the Transpassive State", H. H. Uhlig Award Lecture, The Electrochemical Society Spring Meeting, San Francisco, CA, May, 2001.

35. D. D. Macdonald, "The Holy Grail: Deterministic Prediction of Corrosion Damage Thousands of Years into the Future", Proc. Int. Workshop Pred. Long Term Corros. Behav. Nucl. Waste Systs., (Commissariat a l'Energie Atomique and Pennsylvania State University), Cadarache, France, Nov. 26-29 (2001). Euro. Fed. Corros. Publ. (Ed. D. Ferron and D. D. Macdonald), No. 36, pp 75-90 (2003)

36. H. Tsuchiya, S. Fujimoto, O. Chihara, And T. Shibata, Electrochim. Acta, 47, 4357 (2002).

37. C. Sunseri, S. Piazza, and F. DiQuarto, J. Electrochem. Soc., 137, 2411 (1990).

38. O. Pensado-Rodrguez, O, M. Urquidi-Macdonald, J. R. Flores, and D. D. Macdonald, "Bilayer Film Structure Modeling for Lithium Dissolution in Alkaline Solutions", in Passivity and Its Breakdown, Proc. Electrochem. Soc. (Ed. P. M. Natishan, et al.). Proc. Electrochem. Soc., 97-26, 870-879 (1997).

39. O. Pensado-Rodriguez, J. Flores, M. Urquidi-Macdonald, and D. D. Macdonald, J. Electrochem. Soc., 146, 1326-1335 (1999).

40. P. Park, M. Urquidi-Macdonald, and D. D. Macdonald, ICONE $\left(12^{\text {th }}\right.$ Int. Conf. Nucl. Eng., "Nuclear Energy - Powering the Future"), Hyatt Regency Crystal City, Arlington, VA, USA, April 25-29, 2004, Paper ICONE12-49098 (2004).

41. H. Tsuchiya, S. Fujimoto, O. Chihara, and T. Shibata, Electrochim. Acta, 47, 4357 (2002).

42. D. D. Macdonald, A. Sun, N. Priyantha, and P. Jayaweera, J. Electroanal. Chem., 572, 421 (2004).

43. B. Marx, J. Liu, and D. D. Macdonald, "An Impedance Spectroscopic Study of the Passive State on Iron", in preparation (2005).

44. E. Sikora, and D. D. Macdonald, Electrochim. Acta, 48, 69 (2002).

45. D. D. Macdonald and G. A. Cragnolino. "Corrosion and Erosion-Corrosion of Steam Cycle Materials". Chapter 9 in Water Technology for Thermal Power Systems (Edit. P. Cohen), ASME, New York, NY. (1989).

46. E. Sikora, J. Sikora, and D. D. Macdonald. "The Point Defect Model vs. the High Field Model for Describing the Growth of Passive Films". Proc. $7^{\text {th }}$ Int. Symp. Oxide Films on Metals and Alloys VII. 94-25: 139-151 . (1994). Edited by K. R. Herbert and G. E. Thompson.

47. D. D. Eley and P. R. Wilkinson, Proc. Roy. Soc. (London) Ser. A, 254, 327 (1960). 
Table 1. Gibbs energies of reaction of metals with oxygen and water vapor under prototypical terrestrial conditions $\left[\mathrm{T}=25^{\circ} \mathrm{C}, p_{\mathrm{O}_{2}}=0.21 \mathrm{~atm}, p_{\mathrm{H}_{2} \mathrm{O}}\right.$ $\left.=0.02532 \mathrm{~atm}(\mathrm{RH}=80 \%), p_{H_{2}}=6.156 \times 10^{-42} \mathrm{~atm}\right]$.

\begin{tabular}{|c|c|c|c|}
\hline Metal & Reaction & $\Delta G, \mathrm{M} / \mathrm{O}_{2}(\mathrm{~kJ} / \mathrm{mol})$ & $\Delta G, \mathrm{M} / \mathrm{H}_{2} \mathrm{O}(\mathrm{kJ} / \mathrm{mol})$ \\
\hline $\mathbf{F e}$ & $\begin{array}{l}3 \mathrm{Fe}+2 \mathrm{O}_{2}=\mathrm{Fe}_{3} \mathrm{O}_{4} \\
3 \mathrm{Fe}+4 \mathrm{H}_{2} \mathrm{O}=\mathrm{Fe}_{3} \mathrm{O}_{4}+4 \mathrm{H}_{2}\end{array}$ & -1007.5 & -1005.3 \\
\hline $\mathbf{C r}$ & $\begin{array}{l}2 \mathrm{Cr}+1.5 \mathrm{O}_{2}=\mathrm{Cr}_{2} \mathrm{O}_{3} \\
2 \mathrm{Cr}+3 \mathrm{H}_{2} \mathrm{O}=\mathrm{Cr}_{2} \mathrm{O}_{3}+3 \mathrm{H}_{2}\end{array}$ & -1047.3 & -1045.7 \\
\hline $\mathbf{N i}$ & $\begin{array}{l}\mathrm{Ni}+0.5 \mathrm{O}_{2}=\mathrm{NiO} \\
\mathrm{Ni}+\mathrm{H}_{2} \mathrm{O}=\mathrm{NiO}+\mathrm{H}_{2}\end{array}$ & -209.7 & -209.1 \\
\hline $\mathbf{C u}$ & $\begin{array}{l}2 \mathrm{Cu}+0.5 \mathrm{O}_{2}=\mathrm{Cu}_{2} \mathrm{O} \\
2 \mathrm{Cu}+\mathrm{H}_{2} \mathrm{O}=\mathrm{Cu}_{2} \mathrm{O}+\mathrm{H}_{2}\end{array}$ & -145.9 & -145.4 \\
\hline $\mathbf{A l}$ & $\begin{array}{l}2 \mathrm{Al}+1.5 \mathrm{O}_{2}=\mathrm{Al}_{2} \mathrm{O}_{3} \\
2 \mathrm{Al}+3 \mathrm{H}_{2} \mathrm{O}=\mathrm{Al}_{2} \mathrm{O}_{3}+3 \mathrm{H}_{2}\end{array}$ & -1576.5 & -1574.9 \\
\hline $\mathbf{T i}$ & $\begin{array}{l}\mathrm{Ti}+\mathrm{O}_{2}=\mathrm{TiO}_{2} \\
\mathrm{Ti}+4 \mathrm{H}_{2} \mathrm{O}=\mathrm{TiO}_{2}+4 \mathrm{H}_{2}\end{array}$ & -885.6 & -884.5 \\
\hline$\overline{\mathbf{Z r}}$ & $\begin{array}{l}\mathrm{Zr}+\mathrm{O}_{2}=\mathrm{ZrO}_{2} \\
\mathrm{Zr}+4 \mathrm{H}_{2} \mathrm{O}=\mathrm{ZrO}_{2}+4 \mathrm{H}_{2}\end{array}$ & -1038.6 & -1037.5 \\
\hline $\overrightarrow{\mathbf{P t}}$ & $\begin{array}{l}\mathrm{Pt}+0.5 \mathrm{O}_{2}=\mathrm{PtO} \\
\mathrm{Pt}+\mathrm{H}_{2} \mathrm{O}=\mathrm{PtO}+\mathrm{H}_{2}\end{array}$ & -43.0 & -42.5 \\
\hline $\mathbf{A u}$ & $\begin{array}{l}2 \mathrm{Au}+1.5 \mathrm{O}_{2}=\mathrm{Au}_{2} \mathrm{O}_{3} \\
2 \mathrm{Au}+3 \mathrm{H}_{2} \mathrm{O}=\mathrm{Au}_{2} \mathrm{O}_{3}+3 \mathrm{H}_{2}\end{array}$ & 83.7 & 85.3 \\
\hline
\end{tabular}


Table 2. Rate constants $k_{i}=k_{i}^{0} e^{a_{i} V} e^{b_{i} L} e^{c_{i} p H}$ for the interfacial defect generation and annihilation reactions employed in the Point Defect Model.

\begin{tabular}{|c|c|c|c|}
\hline Reaction & $\begin{array}{l}a_{i} \\
\left(V^{-1}\right)\end{array}$ & $\begin{array}{l}b_{i} \\
\left(\mathrm{~cm}^{-1}\right)\end{array}$ & $c_{i}$ \\
\hline (1) $m+V_{M}^{\chi^{\prime}} \stackrel{k_{1}}{\longrightarrow} M_{M}+v_{m}+\chi e^{\prime}$ & $\alpha_{1}(1-\alpha) \chi \gamma$ & $-\alpha_{1} \chi \varepsilon \gamma$ & $-\alpha_{1} \beta \chi \gamma$ \\
\hline (2) $m \stackrel{k_{2}}{\longrightarrow} M_{i}^{\chi+}+v_{m}+\chi e^{\prime}$ & $\alpha_{2}(1-\alpha) \chi \gamma$ & $-\alpha_{2} \chi \varepsilon \gamma$ & $-\alpha_{2} \beta \chi \gamma$ \\
\hline (3) $m \stackrel{k_{3}}{\longrightarrow} M_{M}+\frac{\chi}{2} V_{\ddot{O}}+\chi e^{\prime}$ & $\alpha_{3}(1-\alpha) \chi \gamma$ & $-\alpha_{3} \chi \varepsilon \gamma$ & $-\alpha_{3} \beta \chi \gamma$ \\
\hline (4) $\quad M_{M} \stackrel{k_{4}}{\longrightarrow} M^{\Gamma+}+(\Gamma-\chi) e^{\prime}$ & $\alpha_{4} \alpha \Gamma \gamma$ & & $\alpha_{4} \beta \Gamma \gamma$ \\
\hline (5) $M_{i}^{\chi+} \stackrel{k_{s}}{\longrightarrow} M^{\Gamma+}+(\Gamma-\chi) e^{\prime}$ & $\alpha_{5} \alpha \Gamma \gamma$ & & $\alpha_{5} \beta \Gamma \gamma$ \\
\hline (6) $V_{\ddot{O}}+H_{2} O \stackrel{k_{6}}{\longrightarrow} O_{O}+2 H^{+}$ & $2 \alpha_{6} \alpha \gamma$ & & $\alpha_{6} \beta \Gamma \gamma$ \\
\hline (7) $\begin{array}{l}M O_{\chi / 2}+\chi H^{+} \stackrel{k_{7}}{\longrightarrow} M^{\Gamma+}+ \\
\frac{\chi}{2} H_{2} O+(\Gamma-\chi) e^{\prime}\end{array}$ & $\alpha_{7} \alpha(\Gamma-\chi) \gamma$ & & $\alpha_{7} \beta(\Gamma-\chi) \gamma$ \\
\hline
\end{tabular}

Table 3. Definition of the standard rate constants for the interfacial defect generation and annihilation reactions employed in the Point Defect Model. Note that the base rate constant for the $i^{\text {th }}$ reaction is designated $k_{i}^{00}$.

\begin{tabular}{|c|c|}
\hline Reaction & $k_{i}^{0}$ \\
\hline (1) $\quad m+V_{M}^{\chi^{\prime}} \stackrel{k_{I}}{\longrightarrow} M_{M}+v_{m}+\chi e^{\prime}$ & $k_{l}^{00} e^{-\alpha_{1} \chi \gamma \phi_{f / s}^{0}}$ \\
\hline (2) $\quad m \stackrel{k_{2}}{\longrightarrow} M_{i}^{\chi+}+v_{m}+\chi e^{\prime}$ & $k_{2}^{O 0} e^{-\alpha_{2} \chi \gamma \phi_{f / s}^{0}}$ \\
\hline (3) $\quad m \stackrel{k_{3}}{\longrightarrow} M_{M}+\frac{\chi}{2} V_{\ddot{O}}+\chi e^{\prime}$ & $k_{3}^{00} e^{-\alpha_{3} \chi \gamma \phi_{f / s}^{0}}$ \\
\hline (4) $\quad M_{M} \stackrel{k_{4}}{\longrightarrow} M^{\Gamma+}+(\Gamma-\chi) e^{\prime}$ & $k_{4}^{00} e^{\alpha_{4} \Gamma \gamma \phi_{f / s}^{0}}$ \\
\hline (5) $\quad M_{i}^{\chi+} \stackrel{k_{5}}{\longrightarrow} M^{\Gamma+}+(\Gamma-\chi) e^{\prime}$ & $k_{5}^{00} e^{\alpha_{5} \Gamma \gamma \phi_{f / s}^{0}}$ \\
\hline (6) $\quad V_{\ddot{O}}+\mathrm{H}_{2} \mathrm{O} \stackrel{k_{6}}{\longrightarrow} \mathrm{O}_{\mathrm{O}}+2 \mathrm{H}^{+}$ & $k_{6}^{00} e^{\alpha_{6} \Gamma \gamma \phi_{f / s}^{0}}$ \\
\hline (7) $M O_{\chi / 2}+\chi H^{+} \stackrel{k_{7}}{\longrightarrow} M^{\Gamma+}+\frac{\chi}{2} H_{2} O+(\Gamma-\chi) e^{\prime}$ & $k_{7}^{00} e^{\alpha_{7}(\Gamma-\chi) \gamma \phi_{f / s}^{0}}$ \\
\hline
\end{tabular}


Table 4. PDM Parameter Values for Alloy X.

\begin{tabular}{|c|c|c|c|}
\hline Parameter & Value & Units & Identity/Origin \\
\hline $\bar{\Omega}$ & 14.59 & $\mathrm{~cm}^{3} / \mathrm{mol}$ & $\begin{array}{l}\text { Mol volume per cation of the barrier layer } \\
\left(\text { Calc. for } \mathrm{Cr}_{2} \mathrm{O}_{3}{ }^{1}\right) \text {. }\end{array}$ \\
\hline$\alpha$ & 0.70 & & Polarizability of the barrier layer/solution \\
\hline$\beta$ & -0.005 & $\mathrm{~V}$ & $\begin{array}{l}\text { Dependence of the potential drop at } \mathrm{bl} / \mathrm{sol} \\
\text { interface on } \mathrm{pH} \text {. }\end{array}$ \\
\hline$\alpha_{1}$ & 0.15 & & Transfer coefficient for Reaction 1 \\
\hline$\alpha_{2}$ & 0.110 & & Transfer coefficient for Reaction 2. \\
\hline$\alpha_{3}$ & 0.120 & & Transfer coefficient for Reaction 3. \\
\hline$\alpha_{4}$ & 0.15 & & Transfer coefficient for Reaction 4. \\
\hline$\alpha_{5}$ & 0.15 & & Transfer coefficient for Reaction 5. \\
\hline$\alpha_{6}$ & 0.15 & & Transfer coefficient for Reaction 5 . \\
\hline$\alpha_{7}$ & 0.50 & & Transfer coefficient for Reaction 7 \\
\hline$\chi$ & 3 & & Oxidation state of cation in barrier layer \\
\hline $\begin{array}{l}\Gamma \\
\varepsilon\end{array}$ & $\begin{array}{l}3 \text { or } 6 \\
2.00 \mathrm{e} 6\end{array}$ & $\mathrm{~V} / \mathrm{cm}$ & $\begin{array}{l}\text { Oxidation state of cation in solution } \\
\text { Electric field strength }\end{array}$ \\
\hline$k_{1}^{00}$ & $5.00 \mathrm{e}-06$ & $\mathrm{~s}^{-1}$ & Base rate constant for Reaction 1. \\
\hline$k_{2}^{00}$ & $1.00 \mathrm{e}-11$ & $\mathrm{~mol} / \mathrm{cm}^{3} . \mathrm{s}$ & $\begin{array}{l}\text { Base rate constant for Reaction } \\
2 .\end{array}$ \\
\hline$k_{3}^{00}$ & $5.00 \mathrm{e}-14$ & $\mathrm{~mol} / \mathrm{cm}^{3} . \mathrm{s}$ & $\begin{array}{l}\text { Base rate constant for film formation, } \\
\text { Reaction } 3 .\end{array}$ \\
\hline$k_{4}^{00}$ & $1.00 \mathrm{e}-16$ & $\mathrm{~mol} / \mathrm{cm}^{3} . \mathrm{s}$ & Base rate constant for Reaction 4. \\
\hline$k_{5}^{00}$ & $1.00 \mathrm{e}-15$ & $\mathrm{~s}^{-1}$ & Base rate constant for Reaction 5 . \\
\hline$k_{6}^{00}$ & $1.00 \mathrm{e}-25$ & $\mathrm{~mol} / \mathrm{cm}^{3} . \mathrm{s}$ & Base rate constant for Reaction 6. \\
\hline$k_{7}^{00}$ & $1.00 \mathrm{e}-13$ & $\mathrm{~mol} / \mathrm{cm}^{3} . \mathrm{s}$ & $\begin{array}{l}\text { Base rate constant for film dissolution, } \\
\text { Reaction } 7 .\end{array}$ \\
\hline $\begin{array}{l}E_{1}-E_{7} \\
n\end{array}$ & $\begin{array}{l}25.1 \\
0.6\end{array}$ & $\mathrm{~kJ} / \mathrm{mol}$ & $\begin{array}{l}\text { Activation energy for Reactions } 1-7 \text {. } \\
\text { Kinetic order of film dissolution wrt }\left[\mathrm{H}^{+}\right] \text {. }\end{array}$ \\
\hline$\phi_{f / s}^{0}$ & -0.1 & V & Constant ${ }^{4}$ \\
\hline
\end{tabular}

1. $\Omega=$ Mol. Wt./density. 


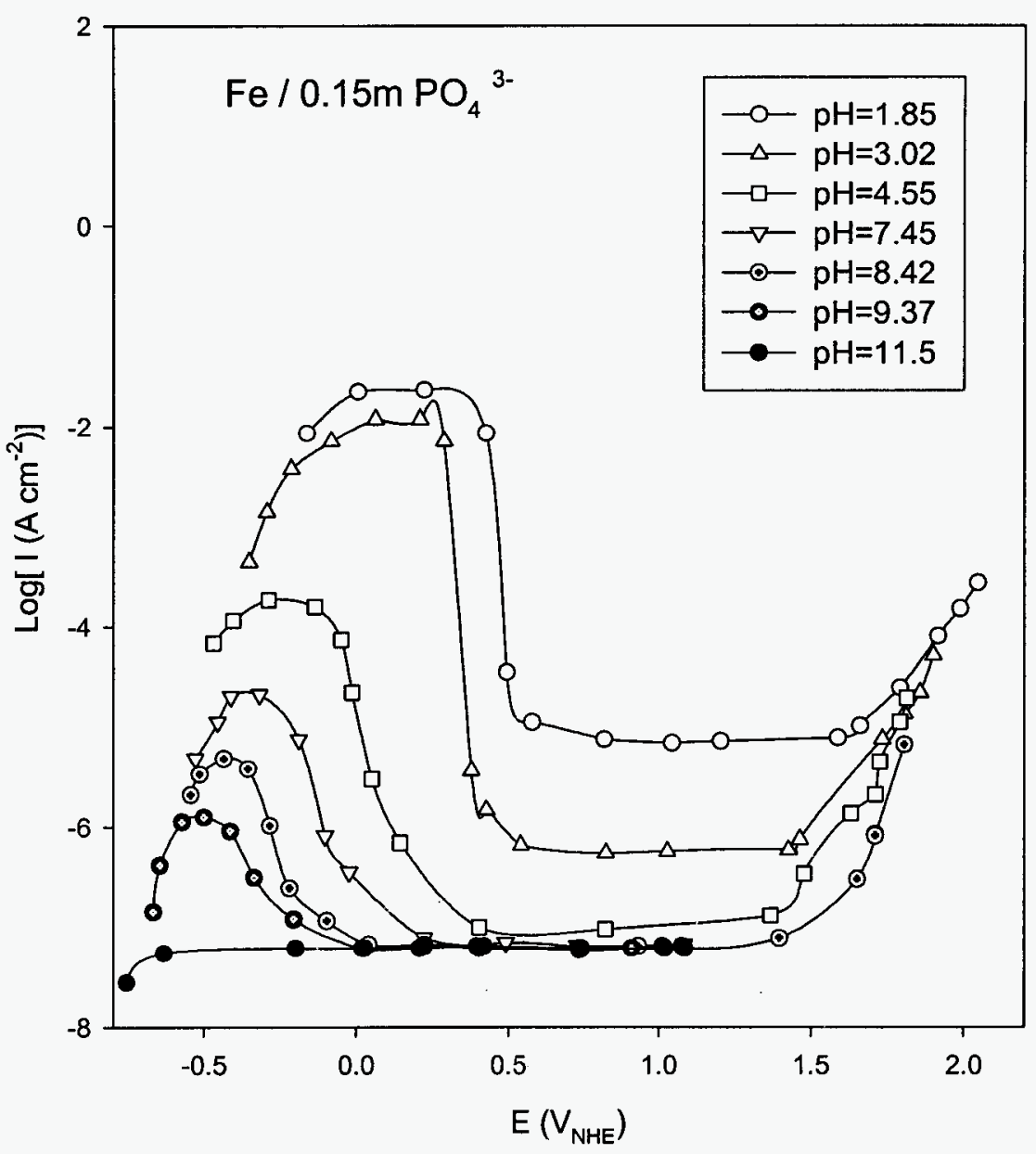

Figure 1: Polarization curves for iron in phosphoric acid/sodium hydroxide buffer solutions at $25^{\circ} \mathrm{C}$ as a function of $\mathrm{pH}$ (data taken from Sato [30]). 
(1) $m+V_{M}^{\chi^{\prime}} \stackrel{k_{l}}{\longrightarrow} M_{M}+v_{m}+\chi e^{\prime}$

(2) $m \stackrel{k_{2}}{\longrightarrow} M_{i}^{\chi+}+v_{m}+\chi e^{-}$

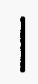

(3) $m \stackrel{k_{3}}{\longrightarrow} M_{M}+\frac{\chi}{2} V_{\ddot{o}}+\chi e^{-}$

(7) $\mathrm{MO}_{\chi / 2}+\chi \mathrm{H}^{+} \stackrel{k_{7}}{\longrightarrow} M^{\Gamma+}+\frac{\chi}{2} \mathrm{H}_{2} \mathrm{O}+(\Gamma-\chi) e^{-}$
(4) $M_{M} \stackrel{k_{\ddagger}}{\longrightarrow} M^{\Gamma+}+V_{M}^{\chi^{\prime}}+(\Gamma-\chi) e^{-}$

(5) $M_{i}^{\chi+} \stackrel{k_{5}}{\longrightarrow} M^{\Gamma+}+(\Gamma-\chi) e^{-}$

(6) $\mathrm{V}_{\ddot{O}}+\mathrm{H}_{2} \mathrm{O} \stackrel{k_{6}}{\longrightarrow} \mathrm{O}_{\mathrm{O}}+2 \mathrm{H}^{+}$

Figure 2: Interfacial defect generation/annihilation reactions that are postulated to occur in the growth of anodic barrier oxide films according to the Point Defect Model [3]. $m=$ metal atom, $V_{M}^{\chi^{\prime}}=$ cation vacancy on the metal sublattice of the barrier layer, $M_{i}^{\chi+}=$ interstitial cation, $M_{M}=$ metal cation on the metal sublattice of the barrier layer, $V_{O} \ddot{*}=$ oxygen vacancy on the oxygen sublattice of the barrier layer, $O_{O}=$ oxygen anion on the oxygen sublattice of the barrier layer, $M^{\Gamma+}=$ metal cation in solution. 


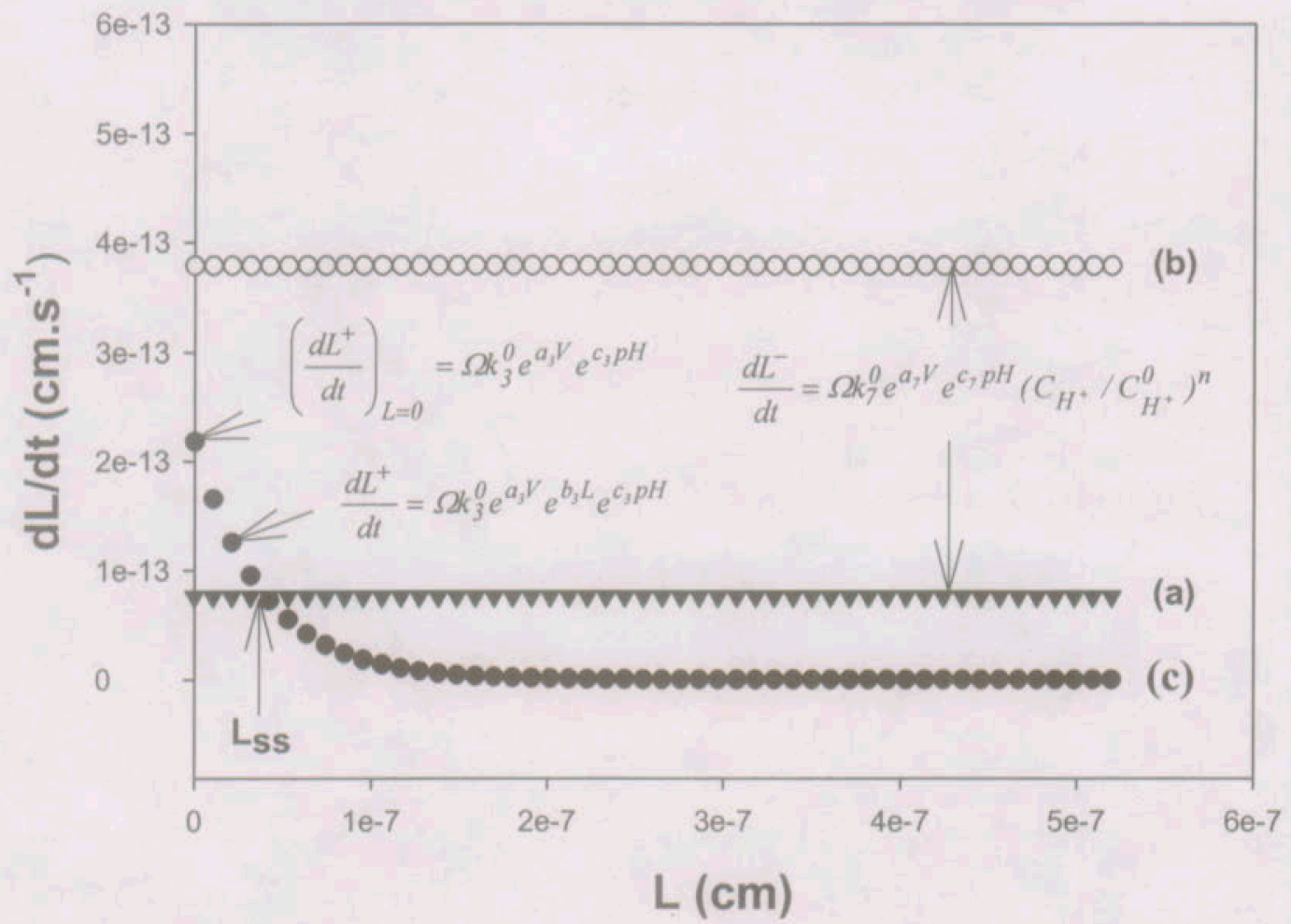

Figure 3: Schematic of phase space analysis showing the steady state, passive condition (filled points, a and $\mathbf{c}$ ) and the depassivated condition (filled and open circles, $\mathbf{c}$ and b). The intersection of (a) and (c) defines the steady state thickness of the metastable barrier layer. No intersection occurs between $\mathbf{b}$ and $\mathbf{c}$ for $L>0$, so that a passive film cannot exist, even in the metastable state. 

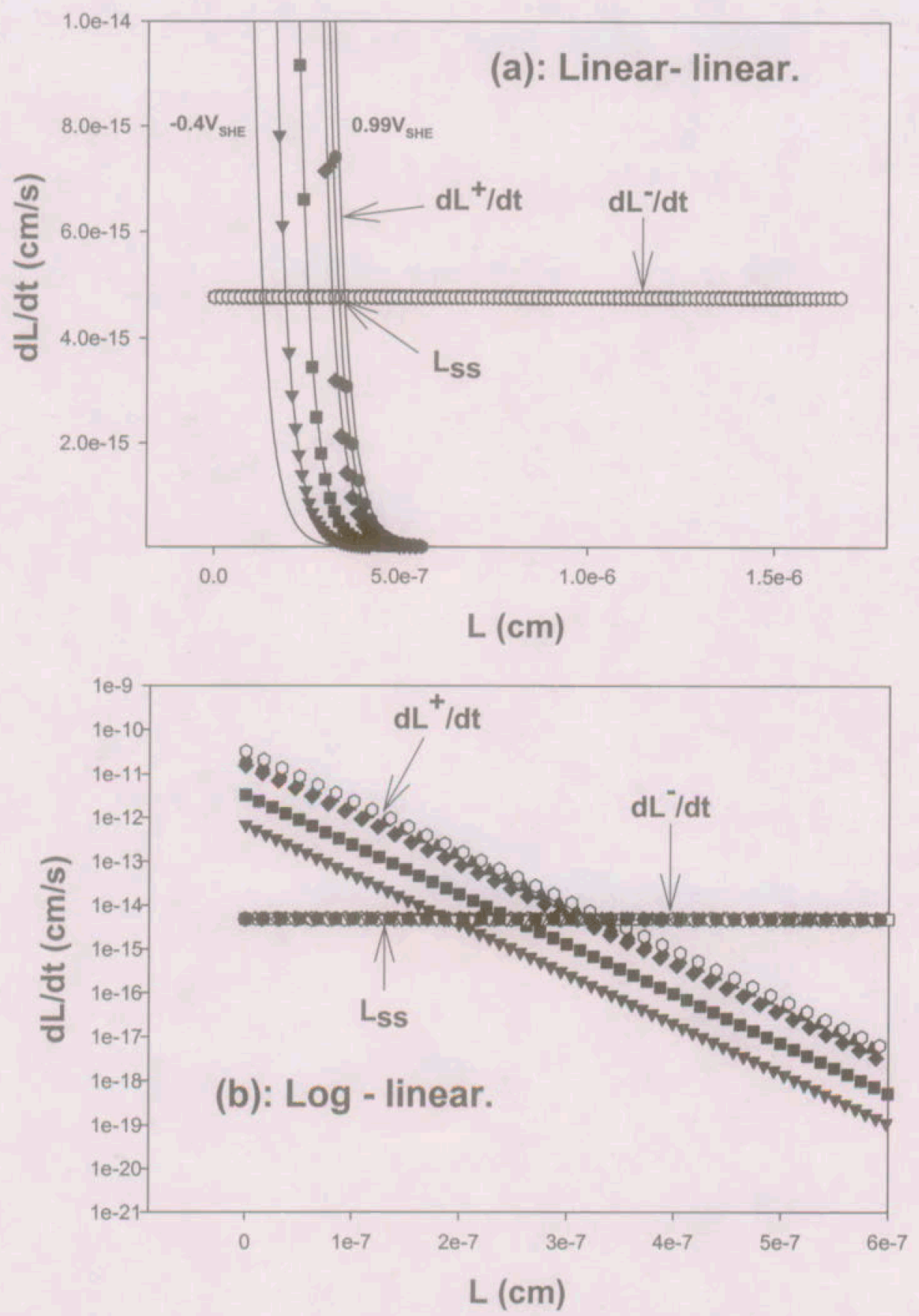

Figure 4: Linear-linear (a) and $\log$-linear (b) phase space plot for the barrier layer on Alloy $\mathrm{X}$ in acidified $(\mathrm{pH}=3), 6.256 \mathrm{~m}$ (sat.) $\mathrm{NaCl}$ at $50^{\circ} \mathrm{C}$, as a function of applied potential. The parameter values used in the calculation are given in Table 4. Note that an intersection occurs between $d L^{+} / d t$ and $d L^{-} / d t$, so that a metastable barrier layer exists in all cases. 


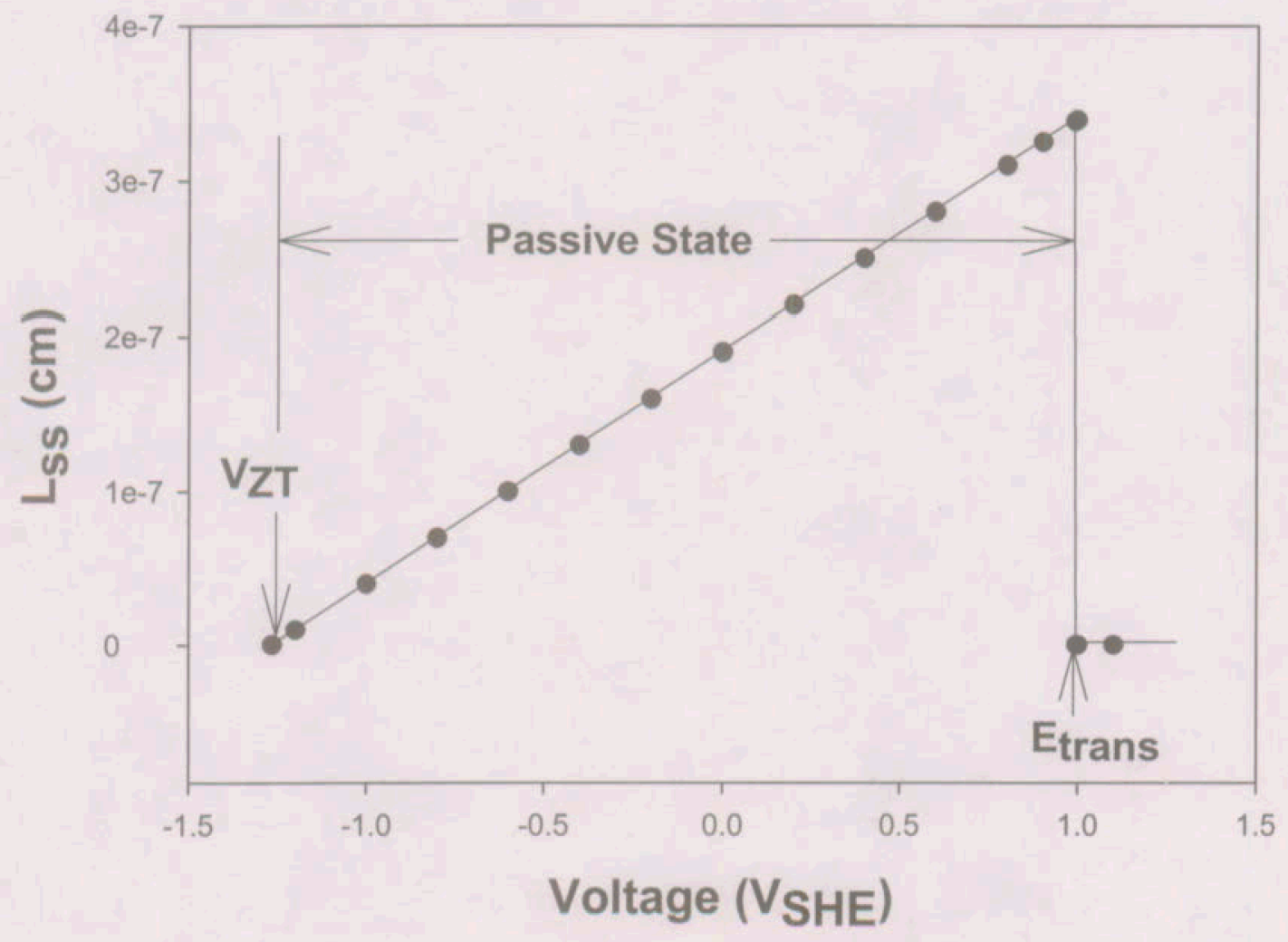

Figure 5. Plot of the predicted steady state barrier layer thickness as a function of voltage. Loss of passivity is predicted to occur at $0.9957 \mathrm{~V}_{\mathrm{SHE}}$ ( $\left.E_{\text {trans }}\right)$, corresponding to the sudden reduction in the barrier layer thickness to zero at high potentials, due to the change in oxidation state of the cation in the film from $\chi$ to $\Gamma$, and at $V_{Z T}$, the potential at which the thickness of the barrier layer becomes zero at low potentials, due to the electrochemical reduction of the film. 


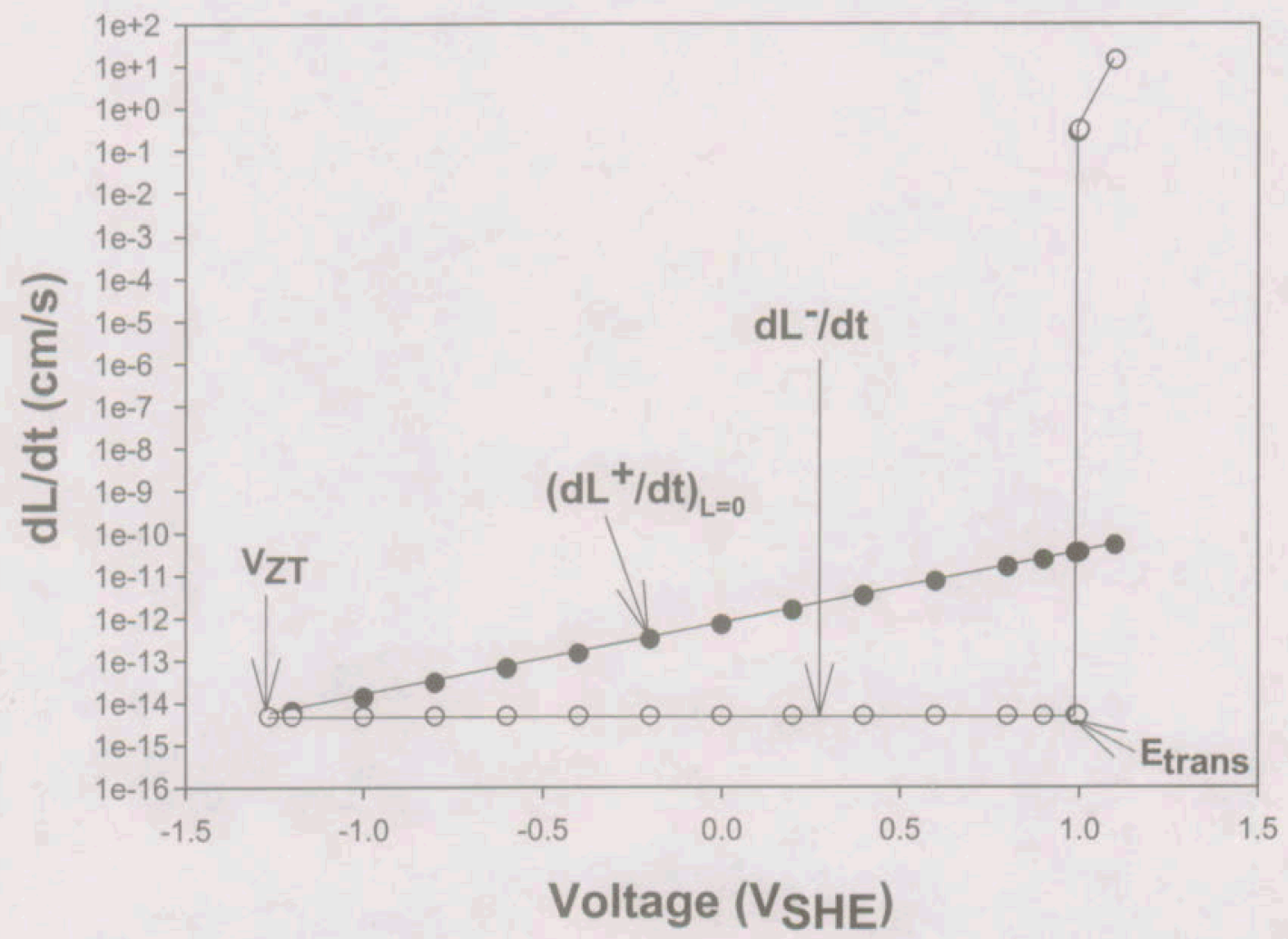

Figure 6: Plots of the initial barrier layer growth rate and dissolution rate as a function of voltage for Alloy $\mathrm{X}$ in $6.256 \mathrm{~m}$ (sat.) $\mathrm{NaCl}$ at $\mathrm{pH} 50^{\circ} \mathrm{C}, \mathrm{pH}$ $=3$. Note that depassivation, corresponding to $d L^{-} / d t>\left(d L^{+} / d t\right)_{L=0}$ (transition into the transpassive state), occurs by the sudden increase in the barrier layer dissolution rate at $E_{\text {trans }}\left(0.9957 \mathrm{~V}_{\mathrm{SHE}}\right)$. Transition to the transpassive state is therefore a catastrophic event. Note also, that the condition of depassivation, $d L^{-} / d t>\left(d L^{+} / d t\right)_{L=0}$ occurs at $\mathrm{V}_{\mathrm{ZT}}=-$ $1.266 \mathrm{~V}_{\mathrm{SHE}}$, but it is not associated with a catastrophic increase in the film dissolution rate. However, in systems that exhibit reductive dissolution, catastrophic dissolution may occur. 

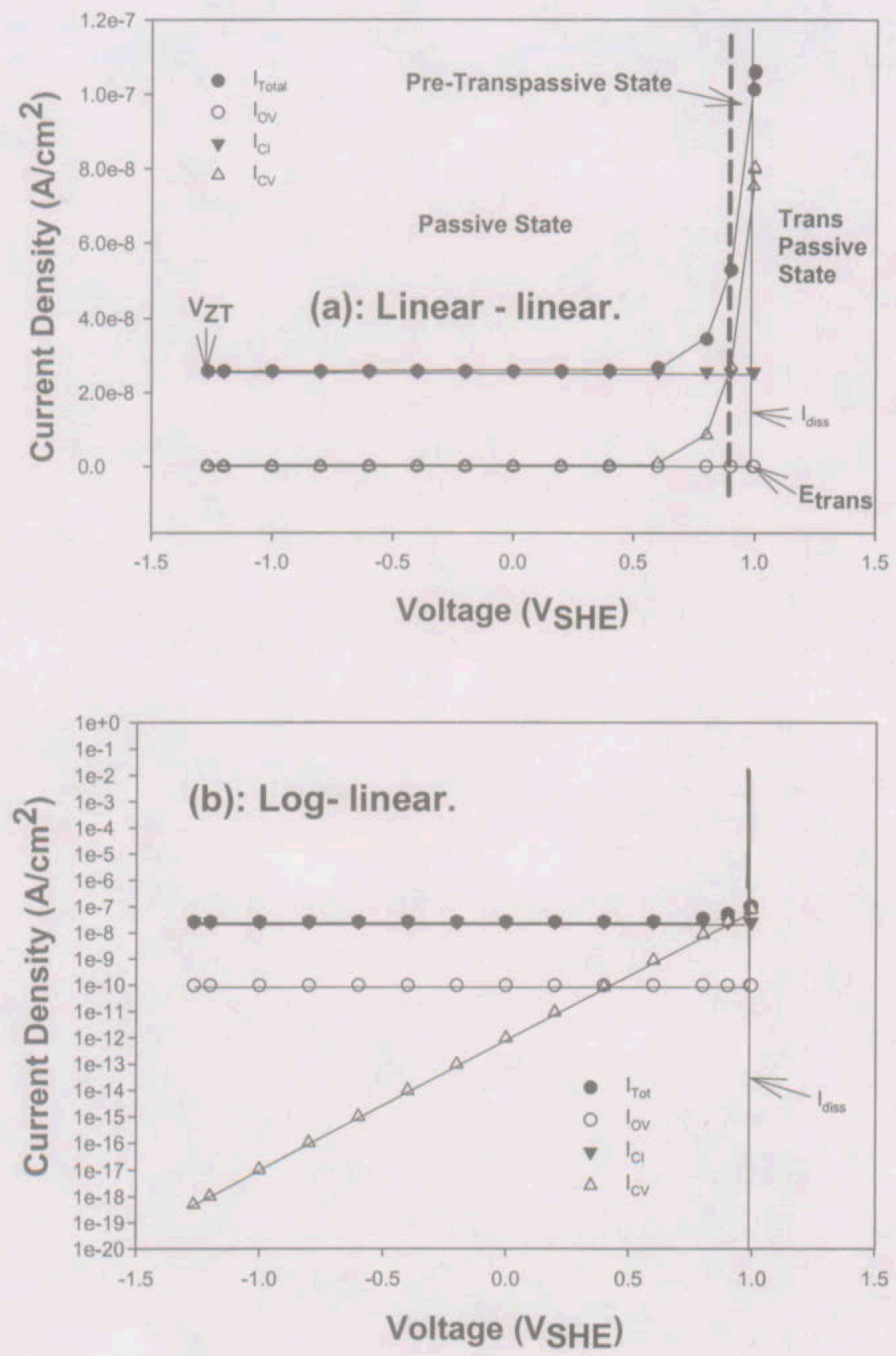

Figure 7: Linear - linear (a) and log - linear plots of the calculated total current density and the partial current densities versus voltage for oxygen vacancy generation $\left(I_{O V}\right)$, cation interstitial generation and annihilation $\left(I_{C l}\right)$,cation vacancy generation and annihilation $\left(I_{C V}\right)$, and the film dissolution (I $I_{\text {diss }}$ ) for Alloy $\mathrm{X}$ in $6.256 \mathrm{~m}$ (sat.) $\mathrm{NaCl}$ at $\mathrm{pH} 50^{\circ} \mathrm{C}, \mathrm{pH}=3$. Note the catastrophic increase in the partial and total currents occurs at E $E_{\text {trans. }}$. 


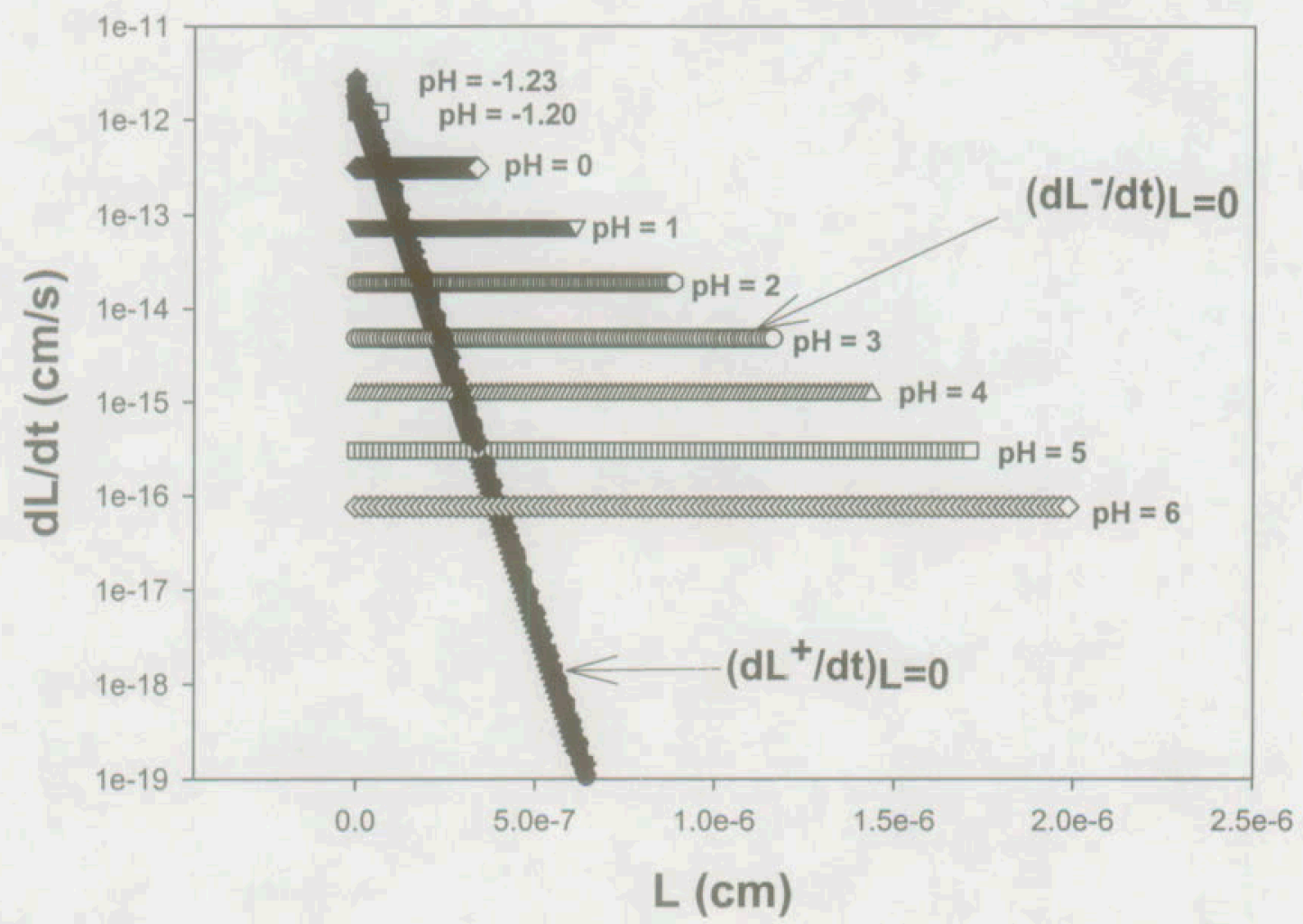

Figure 8: Phase space plots for the barrier layer of the passive film on Alloy $\mathrm{X}$ in $6.256 \mathrm{~m} \mathrm{NaCl}$ (sat.) at $50^{\circ} \mathrm{C}$ and at a potential of $0.300 \mathrm{~V}_{\mathrm{SHE}}$ as a function of $\mathrm{pH}$. 


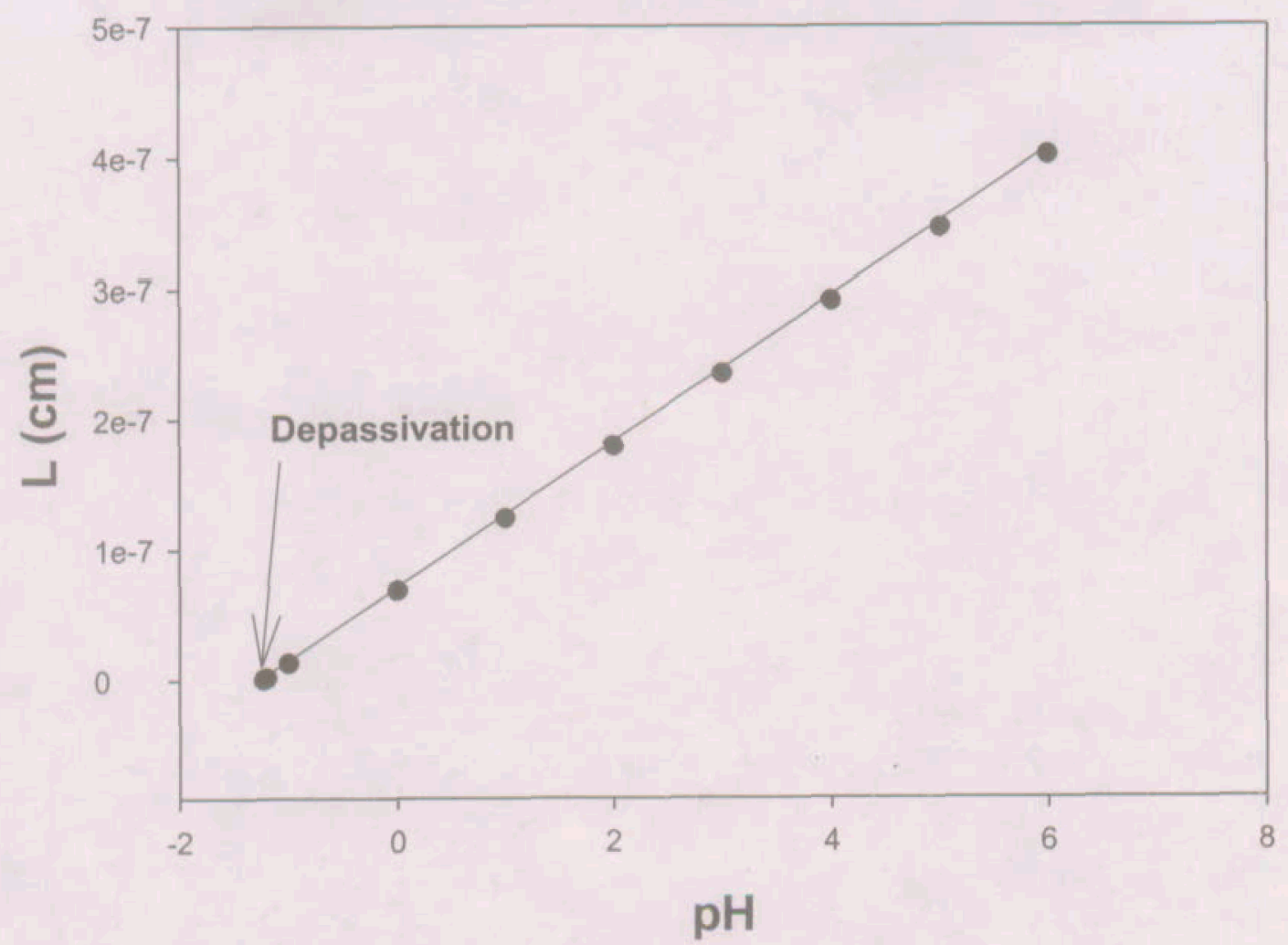

Figure 9: Plot of the steady state thickness of the barrier layer showing the condition for depassivation $\left(L_{s s} \rightarrow 0\right)$, which occurs at $\mathrm{pH}=-1.237$. T $=50^{\circ} \mathrm{C},[\mathrm{NaCl}]=6.256 \mathrm{~m}$ (sat), $\mathrm{V}=0.30 \mathrm{~V}_{\text {SHE }}$. 


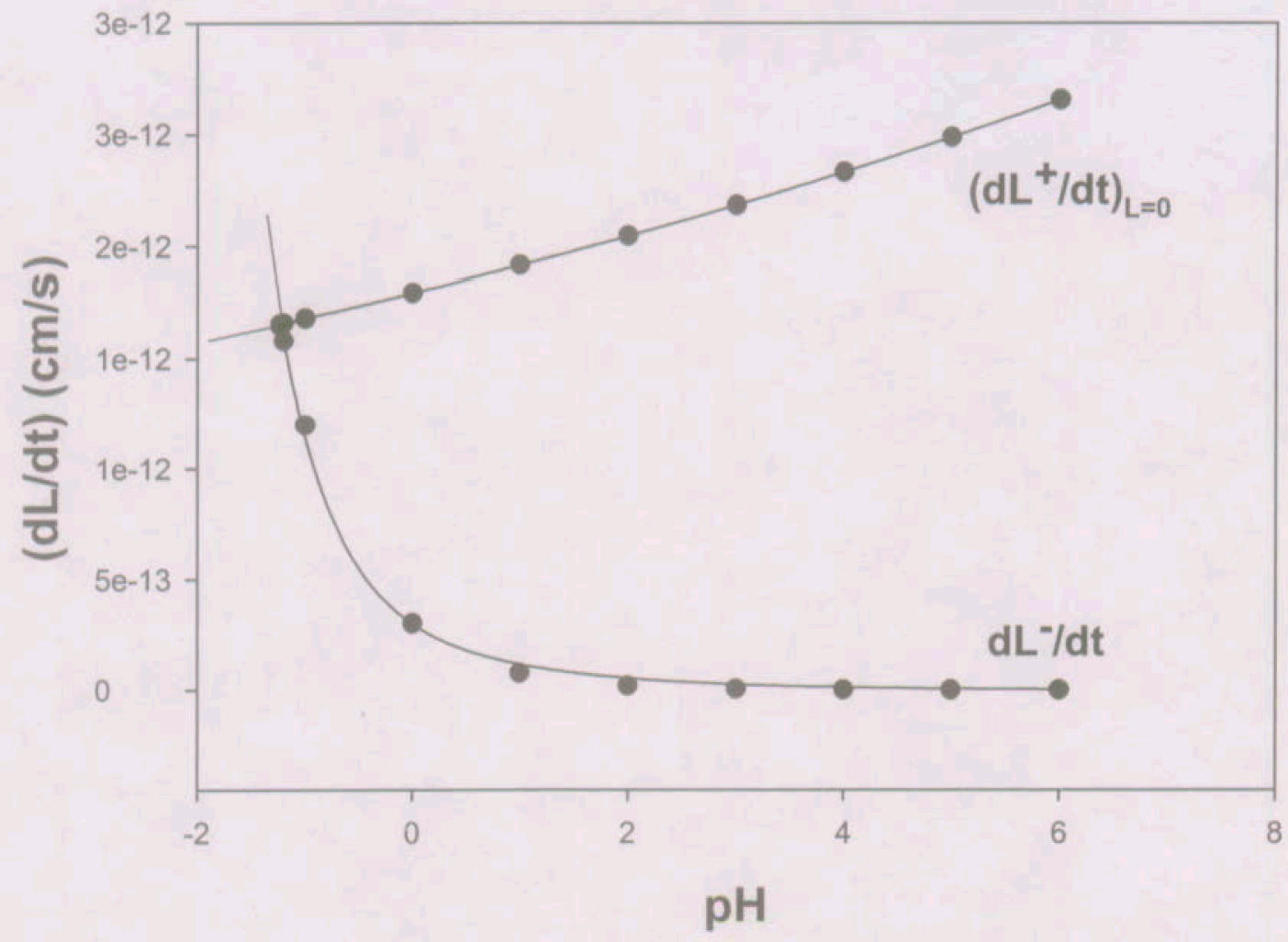

Figure 10: Acid depassivation of Alloy $\mathrm{X}$ in $6.256 \mathrm{~m}$ (sat.) $\mathrm{NaCl}, \mathrm{T}=$ $50^{\circ} \mathrm{C}, \mathrm{V}=0.300 \mathrm{~V}_{\text {SHE }}$. 


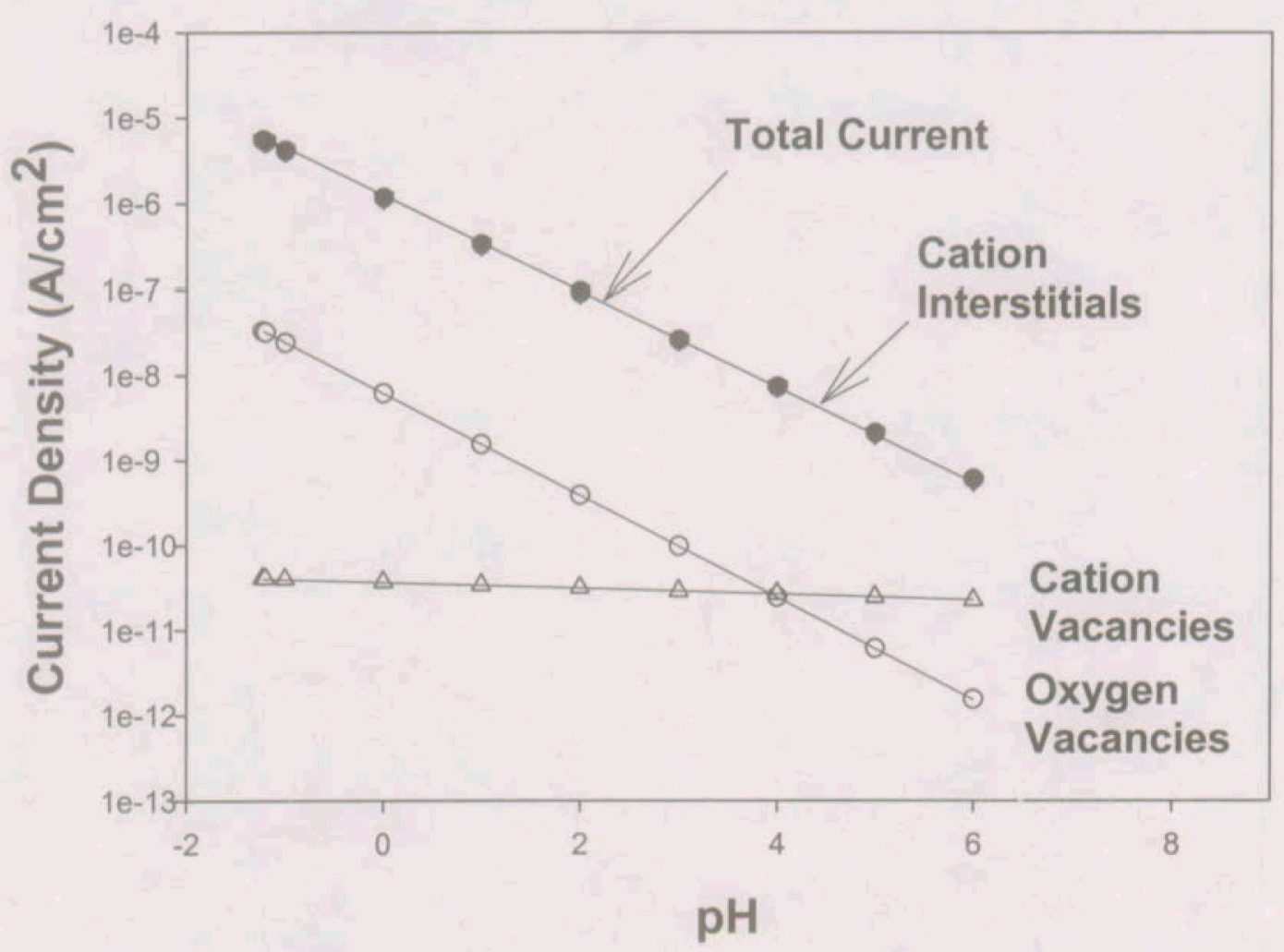

Figure 11: Plots of the partial current densities for cation interstitial, cation vacancy, and oxygen vacancy generation/annihilation and the total current density for Alloy $\mathrm{X}$ in $6.256 \mathrm{~m} \mathrm{NaCl}$ at $50^{\circ} \mathrm{C}$ and at a voltage of $0.30 \mathrm{~V}_{\mathrm{SHE}}$. 


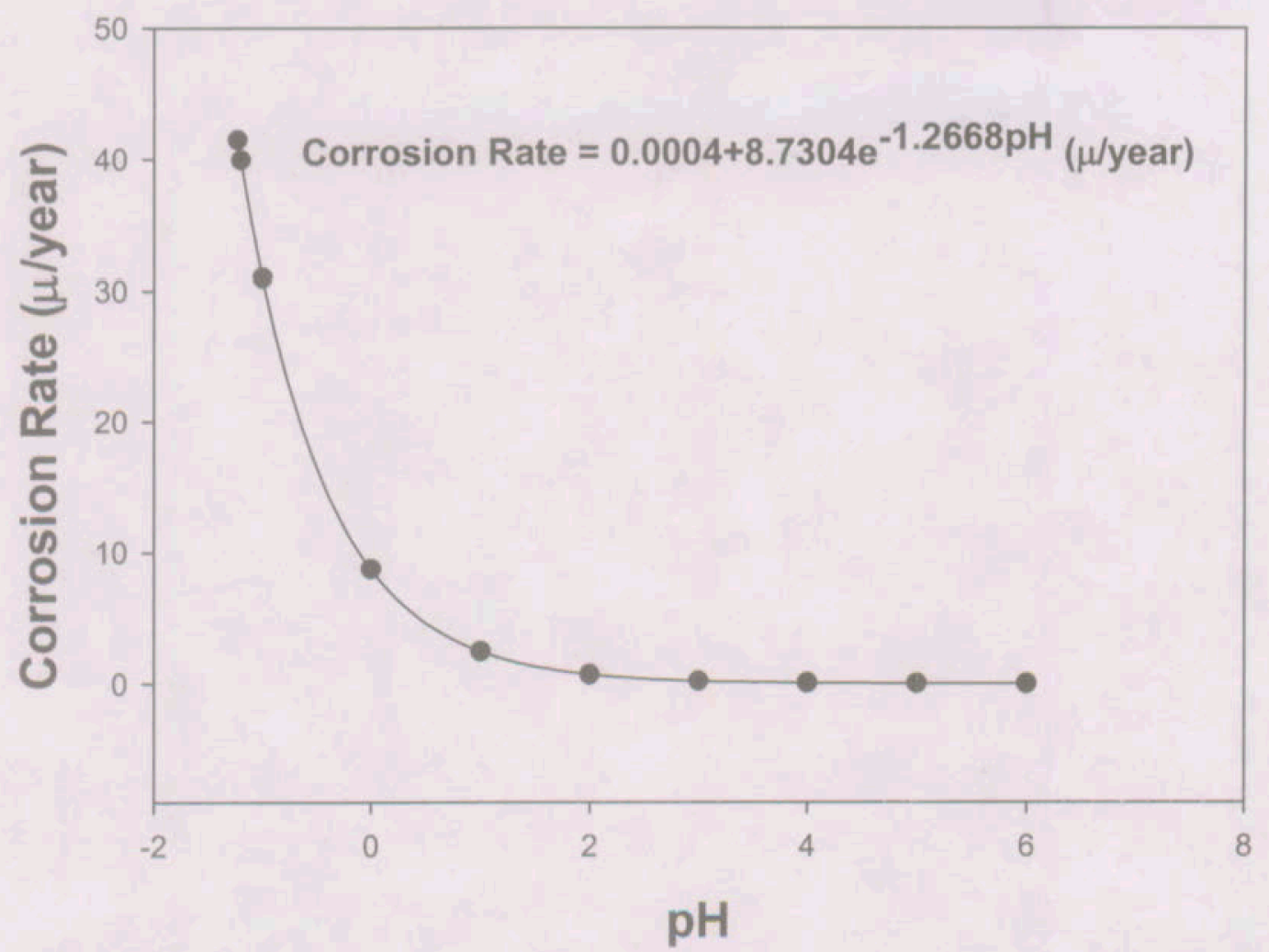

Figure 12: Corrosion rate calculated from the total current density as a function of $\mathrm{pH}$ for Alloy $\mathrm{X}$ in $6.256 \mathrm{~m} \mathrm{NaCl}$ at $50^{\circ} \mathrm{C}, \mathrm{V}=0.30 \mathrm{~V}_{\text {SHE. No }}$ that the corrosion rate is predicted to be a falling exponential function of $\mathrm{pH}$. 


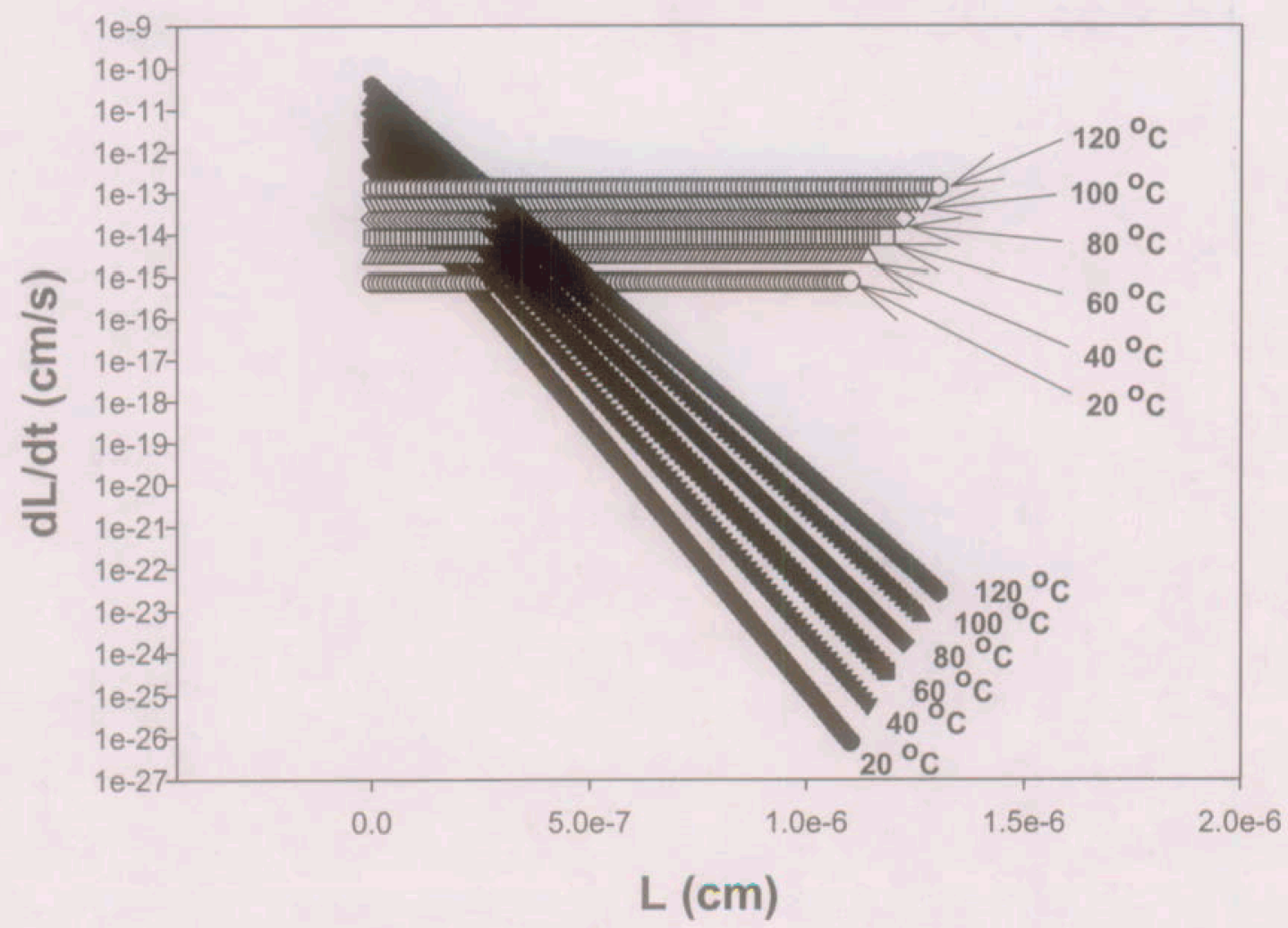

Figure 13: Phase space plots for the barrier layer of the passive film on Alloy $\mathrm{X}$ in $6.256 \mathrm{~m} \mathrm{NaCl}$ (sat.) at a potential of $0.300 \mathrm{~V}_{\text {she }}$ as a function temperature. 


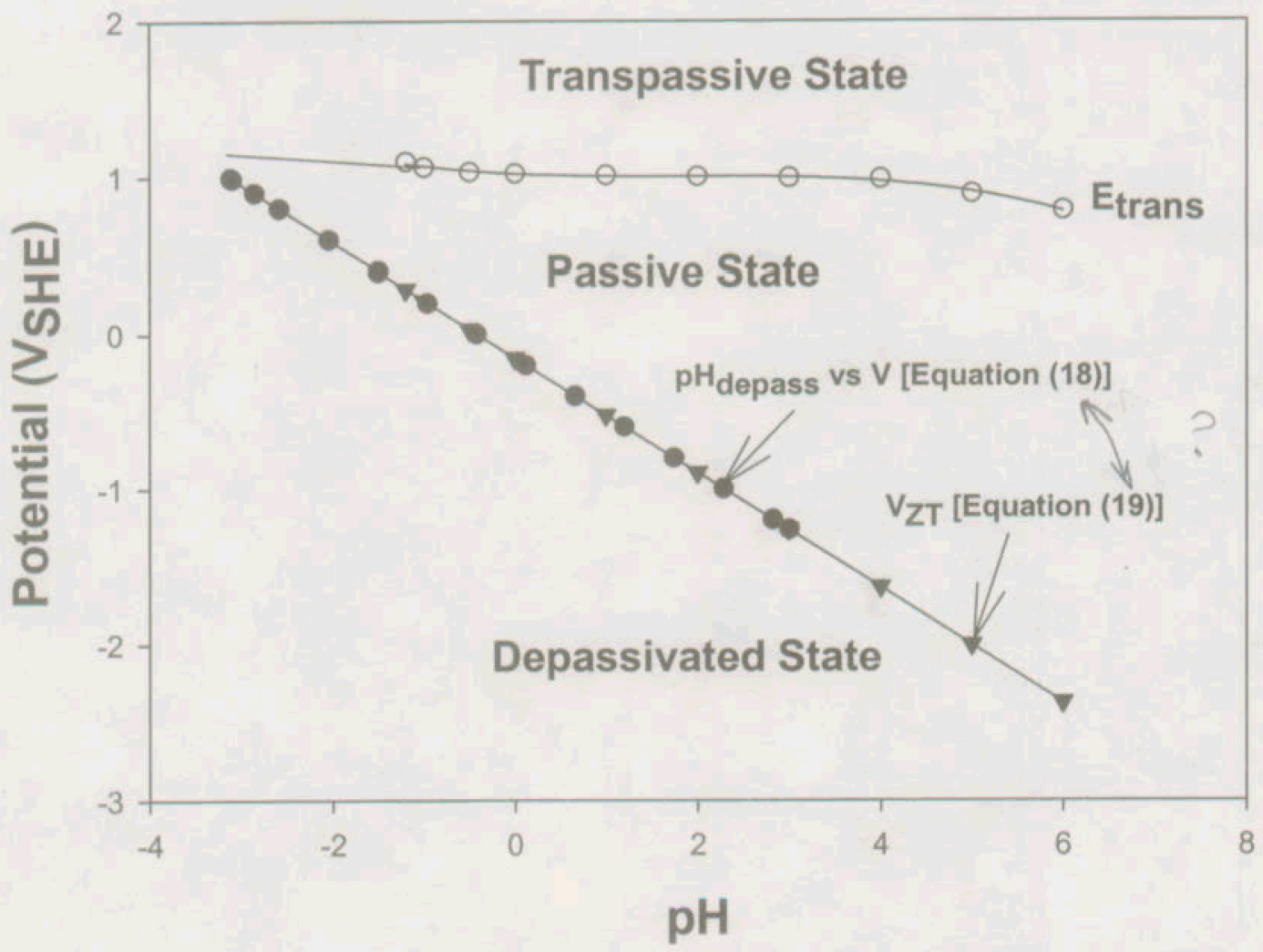

Figure 14: Primitive kinetic stability diagram for Alloy $\mathrm{X}$ in acidic, $6.256 \mathrm{~m} \mathrm{NaCl}$ at $50^{\circ} \mathrm{C}$. The passive state can exist only in the region indicated. 